\title{
Investigation of Stress Arching Above Depleting Hydrocarbon Reservoirs and Its Effect on the Compaction Drive Mechanism
}

Mohammad Hossein Taherynia

Kharazmi University

Seyed Mahmoud Fatemi Aghda ( $\square$ fatemi@khu.ac.ir)

Kharazmi University https://orcid.org/0000-0002-4368-273X

Ahmad Fahimifar

Amirkabir University of Technology

Mohammadreza Koopialipoor

Amirkabir University of Technology

\section{Original Paper}

Keywords: Stress path, Arching coefficient, Compaction drive, Oil recovery, ABAQUS software

Posted Date: February 8th, 2021

DOI: https://doi.org/10.21203/rs.3.rs-187674/v1

License: (c) (i) This work is licensed under a Creative Commons Attribution 4.0 International License. Read Full License

Version of Record: A version of this preprint was published at Geotechnical and Geological Engineering on June 18th, 2021. See the published version at https://doi.org/10.1007/s10706-021-01876-y. 


\section{Investigation of Stress Arching above Depleting Hydrocarbon Reservoirs and its Effect on the Compaction Drive Mechanism}

Mohammad Hossein Taherynia ${ }^{1}$, Seyed Mahmoud Fatemi Aghda ${ }^{1,3}$, Ahmad Fahimifar $^{2}$, and Mohammadreza Koopialipoor ${ }^{2}$

${ }^{1}$ Department of Geological Sciences, Kharazmi University, Tehran, Iran.

${ }^{2}$ Department of Civil Engineering, Amirkabir University of Technology, Tehran, Iran;

${ }^{3}$ To whom correspondence should be addressed; Email: Fatemi@khu.ac.ir, TEL:+989121236292 


\section{Abstract}

In this paper, the compression drive mechanism, which can be considered as the most related oil drive mechanism with the reservoir geomechanical properties, has been investigated. The constant total vertical stress on the reservoir and uniaxial reservoir compaction with zero lateral strain are two main assumptions in the conventional reservoir compaction modeling. These assumptions are not considering the stress arching, which leads to a reduction in the total vertical stress and also affects the distribution of vertical and horizontal stresses. In this paper, it was tried to investigate the effects of three keys elastic parameters, including Young's modulus, Poisson's ratio, and Biot coefficient on the reservoirs stress paths and compaction drive mechanism using numerical modeling with ABAQUS software. Based on the modeling results the reservoirs stress paths is very different from simplifying assumption in uniaxial compaction models while the total compaction of reservoir obtained using numerical modeling and uniaxial model in some cases can be equal. Also, among the three geomechanical parameters, the ratio of Young's modulus of the reservoir and surrounding rocks has a significant effect on the reservoir stress paths and compaction. The results of modeling indicate when a reservoir rock is softer than its surrounding environment, due to the arching occurrence, the total vertical stress applied to the reservoir rock reduced even to half of the initial vertical stress, which leads to the oil recovery by the compression drive mechanism will be less than $50 \%$ of the predicted value.

KEY WORDS: Stress path; Arching coefficient; Compaction drive; Oil recovery; ABAQUS software.

\section{1- Introduction}

The compaction of reservoir rock is a known mechanism for the extraction of oil content of the rock pores. For true calculation of compaction of a depleting reservoir in addition to the 
determination of its compressibility parameters, accurate estimation of the stress changes with reservoir pore pressure dropping is necessary. The state of stresses and its change during depletion of the reservoir have an important impact on oil recovery, directly through compaction drive and indirectly through permeability change (Holt et al. 2004). Also, the state of stresses and its changing trend affect the stability of wells during drilling and production, cap rock integrity, production-induced faulting, and formation particle production (Haug et al. 2018; Radwan and Sen 2020).

Conventionally, in reservoir compaction modeling, the vertical stress on the reservoir is assumed to be constant. With this assumption, the increase in effective stress on the reservoir rock is equal to the decrease in pore pressure multiplied in the Biot coefficient. However, a reduction in total stresses by reducing the pore pressure of the reservoir is indicated in periodic measurements of in situ stresses in different oil fields (Asaei et al. 2018). This decrease is due to stress arching, as a result of which a part of the vertical stress induced from the overburden weight is transmitted to the side burden of the reservoir (Gao and Gray 2020; Sayers and Schutjens 2007). This reduction in acting stresses on the reservoir rock will reduce its compaction relative to the expected value, which leads to not achieving the predicted oil recovery by the compaction drive mechanism.

Numerous studies have been conducted on the stress arching in the last decade, most of which have investigated the effect of this aspect on the stress state in the reservoir, seismic activity by generation or reactivation of faults, and changing the permeability of the reservoir rock (Khan et al. 2000; Mulders 2003; Orlic and Wassing 2013; Peng et al. 2020; Soltanzadeh and Hawkes 2008). Almost these studies have shown that the stress arching in small reservoirs with less stiffness than the surrounding environment is more likely and has a greater impact (Dusseault 2011). Segura et al. (2011) using the numerical 3D modeling investigated the effect of stress arching on reservoir pressure changes. Based on the results of this study, disregarding 
stress arching will cause an overestimate of reservoir pressure in the production period. In this paper, the effects of stress arching on the stress distribution and reservoir compaction are modeled using the ABAQUS software. Also, concerning the importance of compaction drive mechanism, the effect of stress alteration due to stress arching in different parts of the reservoir on the final oil recovery is investigated.

\section{2- Compaction drive mechanism}

Various driving mechanisms are responsible for oil production from reservoir rock, each of which in turn causes the extraction of a part of the in situ oil in the reservoir rock. Four main oil drive mechanisms are included:

1. Depletion drive, which is resulted from the expansion of oil and solution.

2. Segregating gas-cap drive (also called primary gas-cap drive), which has resulted from the expansion of the segregated gas zone.

3. Water drive, which is resulted from the natural aquifer and/or injected water.

4. Compaction drive, which is resulted from the compaction of rock pores when the pressure drops in the reservoir.

The typical participations of each drive mechanism in oil production are shown in Table 1 (Sanni 2018).

Table 1. The participations of drive mechanisms in oil recovery (Sanni 2018)

\begin{tabular}{cc}
\hline Drive mechanism & Recovery of original oil (\%) \\
\hline Depletion drive & $5-25$ \\
Segregated gas-cap drive & $15-40$ \\
Compaction drive & $2-5$ \\
Water drive & $15-60$ \\
\hline
\end{tabular}


Among the mentioned drive mechanisms, compaction drive is in the field of geomechanics and is discussed in this paper. Although in most reservoirs rarely more than $5 \%$ of the total oil recovery are due to the reservoir compaction, in some reservoirs, this mechanism has a significant contribution in the oil recovery.

For example, more than $50 \%$ of oil recovery in the Bachaquero reservoir in Venezuela is due to compaction drive. Also, in the Valhall Reservoir in the Norwegian North Sea, the oil production by compaction drive is estimated at over 70\% (Sanni 2018). The unfortunate aspect of the compaction drive is that compaction of a reservoir can lead to subsidence at the field surface. If the field is located in a desert, the negative effects of subsidence are little, but if the field is located in an urban area or offshore or onshore, subsidence has very negative environmental and economic consequences (Dake 2001). One of the well-known examples of subsidence happens in oil fields that has a consequential major damage to the production platform is the subsidence occurred in the Ekofisk field. The seabed below the active production platforms in the Ekofisk field subsided to more than 3.5 meters in 1984, costs to restore the platform reached to 1 billion dollars (Sulak 1991). The damage caused by subsidence in this field is very prominent and has been mentioned in most related articles. But the important point that is less mentioned about the occurrence of the unanticipated reservoir compaction in the Ekofisk is the impact of reservoir compaction on the oil recovery from this field. The compaction drive in this reservoir caused the recovery of more than $30 \%$ of the oil until 1980, a trend that continued and the economic benefits of this amount of production, which was not anticipated in the development stages of the field, more than compensated for the costly repair (Dake 2001).

According to the mentioned discussion, accurate estimation of the reservoir compaction is important for predicting related problems and exact estimation of oil recovery for field development. 


\section{3- Reservoir stress path and its effect on reservoir compaction}

To better explain the trend of stress changes during the production of a reservoir, the ratio of changes in total stress to the pore pressure reduction is defined as stress path coefficients as below (Hettema et al. 2000):

$$
\begin{gathered}
\gamma_{V}=\frac{\Delta \sigma_{v}}{\Delta p_{f}} \\
\gamma_{H}=\frac{\Delta \sigma_{H}}{\Delta p_{f}}
\end{gathered}
$$

$\gamma_{\mathrm{v}}$ is the vertical stress path coefficient, also called the arching coefficient, and $\gamma_{\mathrm{H}}$ is the horizontal stress path coefficient. The arching coefficient is equal to zero when the total stress remains constant during the production of a reservoir. As was mentioned, one of the two main assumptions in the uniaxial compaction model is neglecting the stress arching and considering $\gamma_{\mathrm{v}}=0$. The secondary assumption in this model is the laterally constraining of the reservoir, and the effective horizontal stresses change in a manner that the horizontal strain is equal to zero. Based on these two assumptions average stress path coefficient can be calculated as (Fjar et al. 2008):

$$
\bar{\gamma}=\frac{2}{3} \frac{1-2 v}{1-v} \alpha
$$

$v$ is the Poisson's ratio coefficient and $\alpha$ is the Biot coefficient.

The compressibility of rock pores $\left(\mathrm{C}_{\mathrm{pp}}\right)$ by taking into account $\Delta \sigma=\bar{\gamma} \Delta \mathrm{p}_{f}$ and also regardless of the rock matrix compressibility due to the large difference between its frame bulk modulus and the solid bulk modulus $\left(\mathrm{K}_{\mathrm{fr}} \ll \mathrm{K}_{\mathrm{s}}\right)$ can be calculated using the following equation (Fjar et al. 2008):

$$
C_{p p}=\frac{1}{V_{p}} \frac{\Delta V_{p}}{\Delta p_{f}}=\frac{1}{\varphi} \frac{1}{3 K_{F R}} \frac{1+v}{1-v}
$$


Where, $\mathrm{V}_{\mathrm{P}}$ is the volume of the reservoir rock pores and $\Delta \mathrm{V}_{\mathrm{p}}$ is its change due to the reduction of pore pressure equal to $\Delta_{\mathrm{pf}}, \varphi$ is porosity, and $\mathrm{K}_{\mathrm{fr}}$ is rock frame compressibility. By determining the $\mathrm{C}_{\mathrm{pp}}$, it is easy to calculate the value of oil production by the compaction drive mechanism using the following equation (Fjar et al. 2008):

$$
\Delta V_{\text {prod }}=-V_{p} C_{p p} \Delta p_{f}
$$

Using relationship for reservoirs in which stress arching has occurred leads to an overestimate of the actual value of oil production per pore pressure drop.

As mentioned, increasing the stress arching coefficient reduces the total stress on the reservoir and thus reduces the compressibility of the reservoir. Equation 4 can be rewritten based on the average stress path coefficient as follows:

$$
C_{p p}=\frac{1-\bar{\gamma}}{\varphi} \frac{1}{K_{F R}}
$$

This relationship confirms that in the uniaxial compaction model of the reservoir if the average stress path increases, the maximum value of which is equal to one, the compressibility value of the reservoir rock pores will tend to zero.

If the vertical stress arching is not considered, in addition to the error caused by zero considering the vertical stress path, a double error will be created due to neglecting the effect of the vertical stress on the horizontal stress paths of a compacting reservoir. Equation 7 shows the relationship between the vertical and horizontal stress paths (Fjar et al. 2008):

$$
\frac{v}{1-v}=\frac{\alpha-\gamma_{h}}{\alpha-\gamma_{v}}
$$

Equation 7 indicates that there is a direct relationship between horizontal and vertical stress coefficients. Based on this relation, by assuming $\gamma_{\mathrm{v}}=0$ the minimum value of the horizontal stress path coefficient is obtained, and the above relation can be rewritten as follows:

$$
\gamma_{h-\min }=\frac{1-2 v}{1-v} \alpha
$$


The above equation is the basis for calculating the mean stress path in relation 3 .

\section{4- Reservoir compaction modeling}

In this paper, the ABAQUS software, that is a powerful set of modeling programs based on the FEM with the ability to solve wide range of problems using linear and nonlinear modeling (Hedayatikhah and Abdideh 2019), was used to model the stress arching phenomenon and its effect on the reservoir compaction. For this purpose, a disk shape reservoir with a height of 200 meters and a redial of 1000 meters located in three different depths of 1000, 2000, 3000 meters were modeled. The overall dimensions of the model and assigned mesh size are shown in Fig 1. Three element types are used for definition different parts of the model: 4- node axisymmetric quadrilateral bilinear pore pressure (CAX4P) for reservoir part, 4-node bilinear axisymmetric quadrilateral (CAX4R) for surrounding of the reservoir, and axisymmetric infinite element type (CINAX4) for bottom and side of the model. With respect to used infinite elements for the far-field, no bindery condition needs to be signed for the base and lateral of the model.

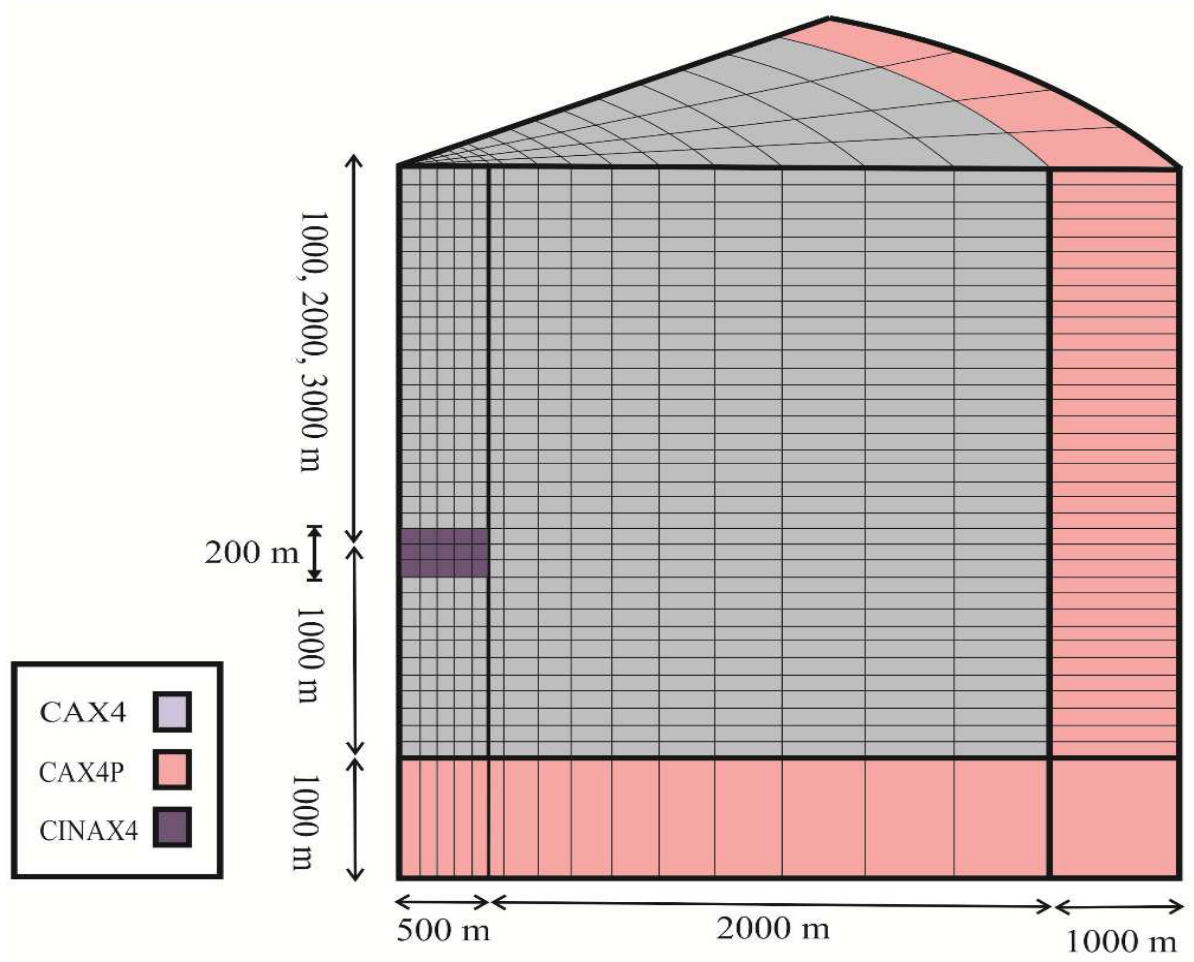

Figure 1. Numerical model: mesh scheme and element type 
In addition to the depth of the reservoir, the ratio of Young's modulus of the reservoir rock $\left(E_{r}\right)$ to its surrounding rock $\left(\mathrm{E}_{\mathrm{s}}\right)$ was also considered as one of the variables in modeling, and models were repeated for three ratios of $\mathrm{E}_{\mathrm{s}} / \mathrm{E}_{\mathrm{r}}=1,5$ and 10. In the first modeling set, the Poisson's ratio of the reservoir and its surrounding rock is considered to be the same and equal to 0.3 , the porosity of the reservoir rock is $25 \%$, and its Young modulus is equal to $5 \mathrm{GPa}$. Also, the initial reservoir pressure was assumed to be $25 \mathrm{MPa}$ at the beginning of production, which reaches 5 $\mathrm{MPa}$ at the end of extraction. Figures 2-4 show the results of the reservoir model located at a depth of $2000 \mathrm{~m}$ with a ratio of $\mathrm{E}_{\mathrm{s}} / \mathrm{E}_{\mathrm{r}}=5$.

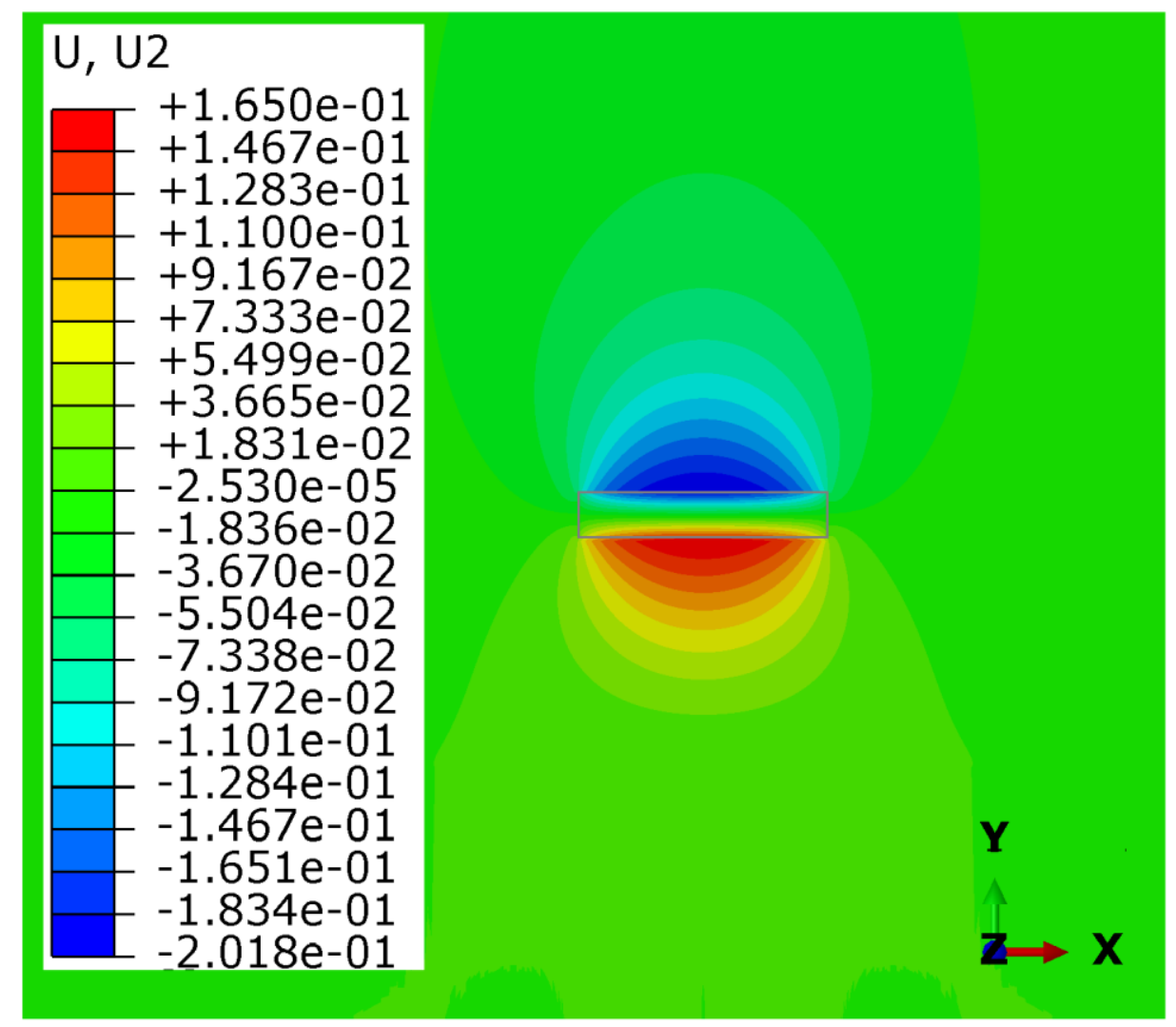

Figure 2. The vertical displacement around the depleted reservoir and raising the lower part of the reservoir due to the vertical stress reduction 


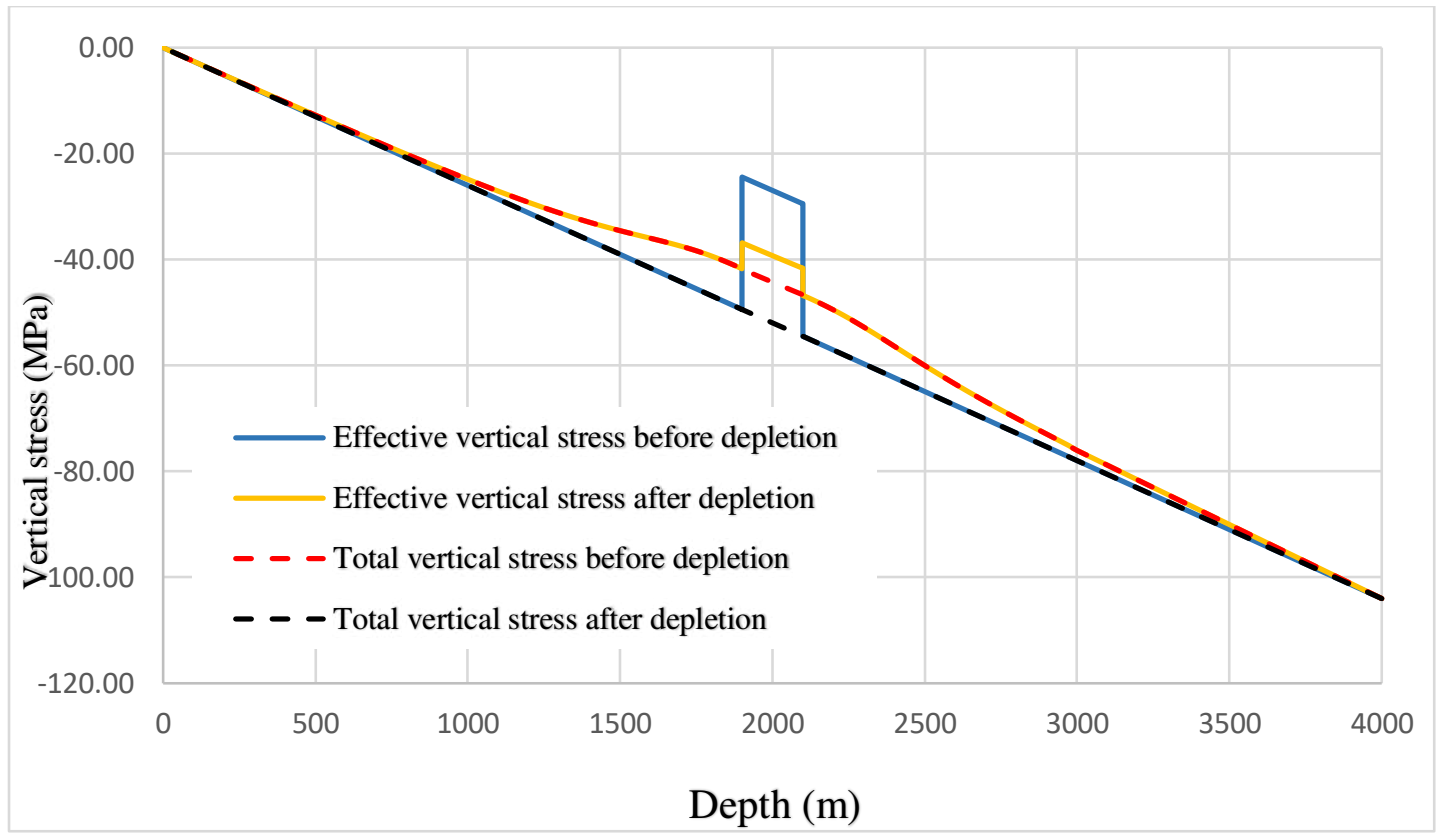

Figure 3. Effective vertical stress changes along the central axis of the reservoir

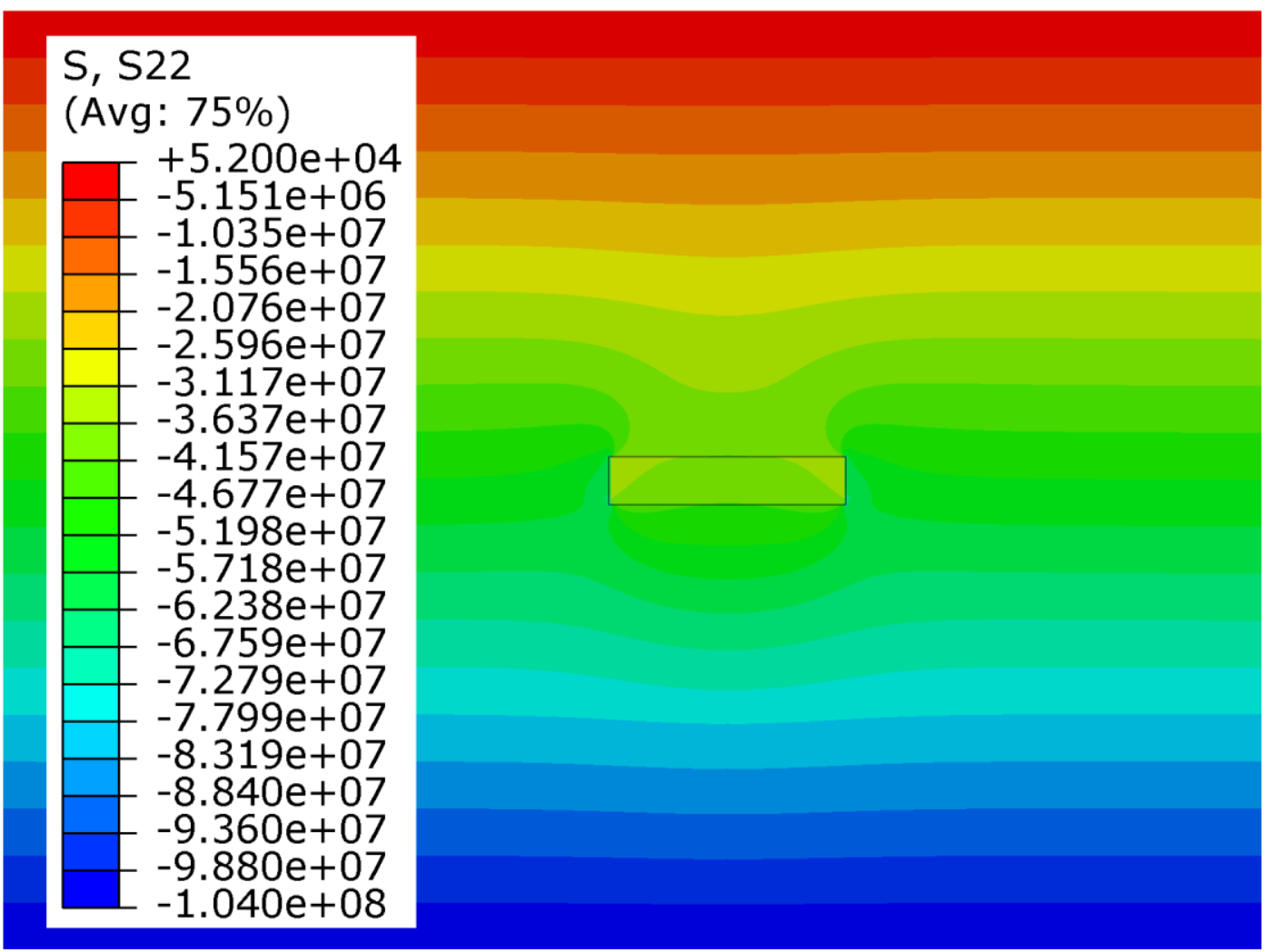

Figure 4. The effective vertical stress changes in the reservoir and its surrounding rock

Figure 2 shows the vertical displacement that occurred in the reservoir and the surrounding rock due to the reservoir withdrawal. Based on the results presented in this Figure, the reservoir 
floor is displaced upwards by reducing the reservoir pore pressure, which indicates the stress arching occurrence in the reservoir overburden and reducing the total vertical stress applied to the reservoir floor. Figure 3 shows the total vertical stress changes along the central axis of the reservoir and Figure 4 shows how the effective vertical stress changes within the reservoir and the surrounding environment. In Figures 3 and 4, the reduction of the vertical stress at the top and bottom of the reservoir due to its depletion can be seen. Figure 4 also shows the increase in the vertical stress on the sides of the reservoir due to the stress arching and transferring a part of the overburden weight to the reservoir flanks. Figure 5 presents the results of the calculation of the vertical stress path for the 9 modeling statuses.

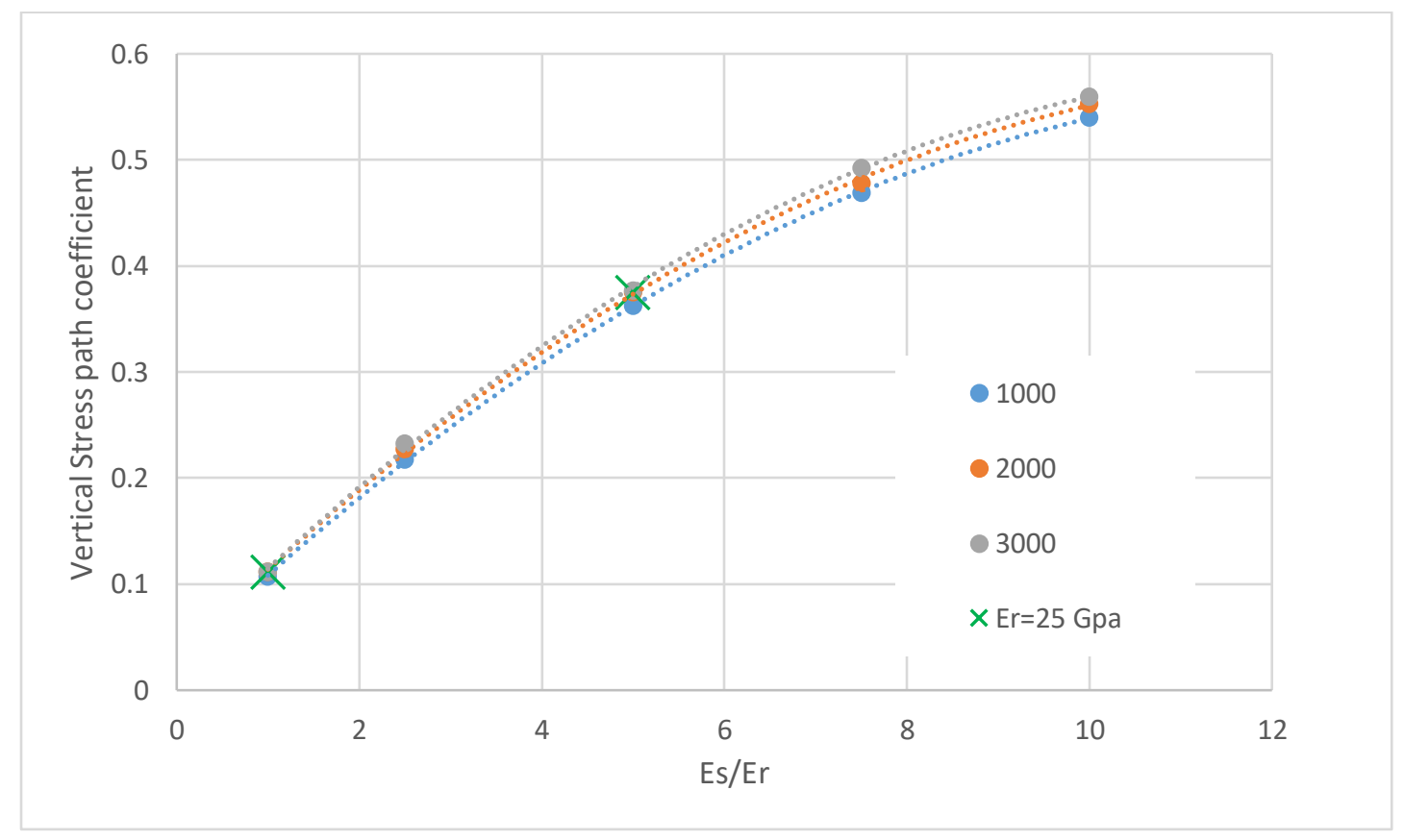

Figure 5. The vertical stress path in different $D / r$ and $E_{s} / E_{r}$ ratios

As can be seen in Figure 5, Young's modulus ratio of the reservoir and the surrounding environment has a significant effect on the arching coefficient, but the aspect ratio (D/r) has not such a tangible effect. Also the modeling results indicates the absolute value of the moduli for a given ratio $E_{\mathrm{r}} / \mathrm{E}_{\mathrm{s}}$, has not a significant effect on the stress path coefficient. For example, arching coefficients of modeled reservoirs in depth of 2000 meters with $\mathrm{E}_{\mathrm{r}} / \mathrm{E}_{\mathrm{s}}=1 \& 5$ and $\mathrm{E}_{\mathrm{r}}=25 \mathrm{GPa}$ are obtained 0.1114 and 0.3750 , respectability. 
Another key elastic parameter that controlled the geomechanical behavior of a reservoir is the Poisson's ratio. The results of molding shown, in addition to the ratio of vr/vs, unlike Young modulus, the absolute values of the Poisson's ratio of the reservoir and the surrounding rock are also affecting the reservoir stress passes. In Figure 6, the arching coefficients calculated on the basis of obtained results from the modeling of a reservoir located at depth $2000 \mathrm{~m}$ and with $\mathrm{E}_{\mathrm{r}}=\mathrm{E}_{\mathrm{s}}=5 \mathrm{GPa}$ are presented. The Poisson's ratios of the reservoir and the surrounding rock are considered equal, $v_{\mathrm{r}} / v_{\mathrm{s}}=1$.

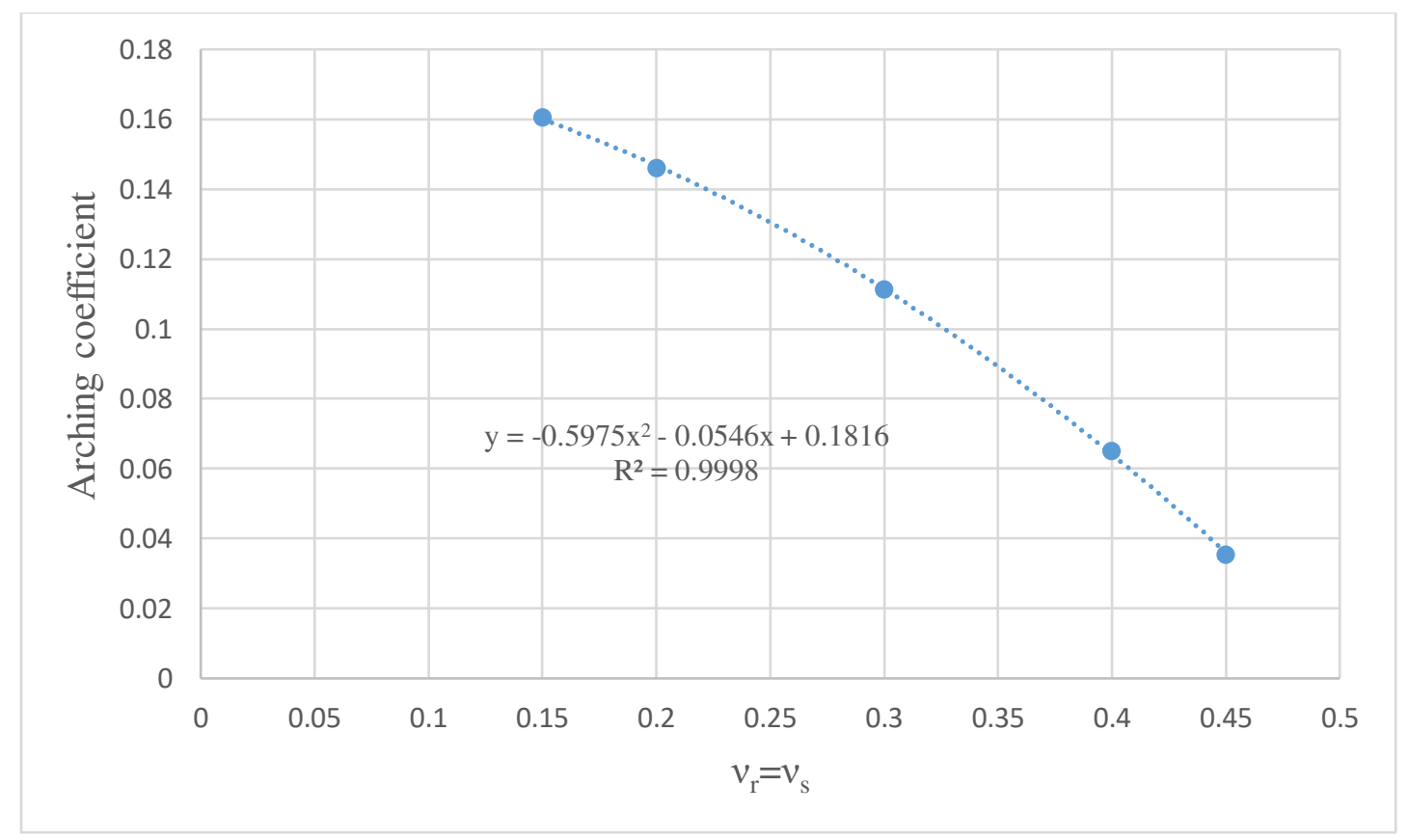

Figure 6. Effect of Poisson's ratio changes in the vertical stress path coefficient.

As shown in Figure 6 with increasing Poisson's ratio of the reservoir and the surrounding rock, the arching coefficient will be decreased.

Also, the modeling results indicated that there is a linear relationship between the arching coefficient and the $v_{\mathrm{r}}$ when the Poisson's ratio of the surrounding rock $\left(v_{\mathrm{s}}\right)$ is considered constant. In Figure 7 variations of the stress arching coefficient are shown for reservoirs with three different $v_{\mathrm{r}}=0.2,0.3$, and 0.4. 


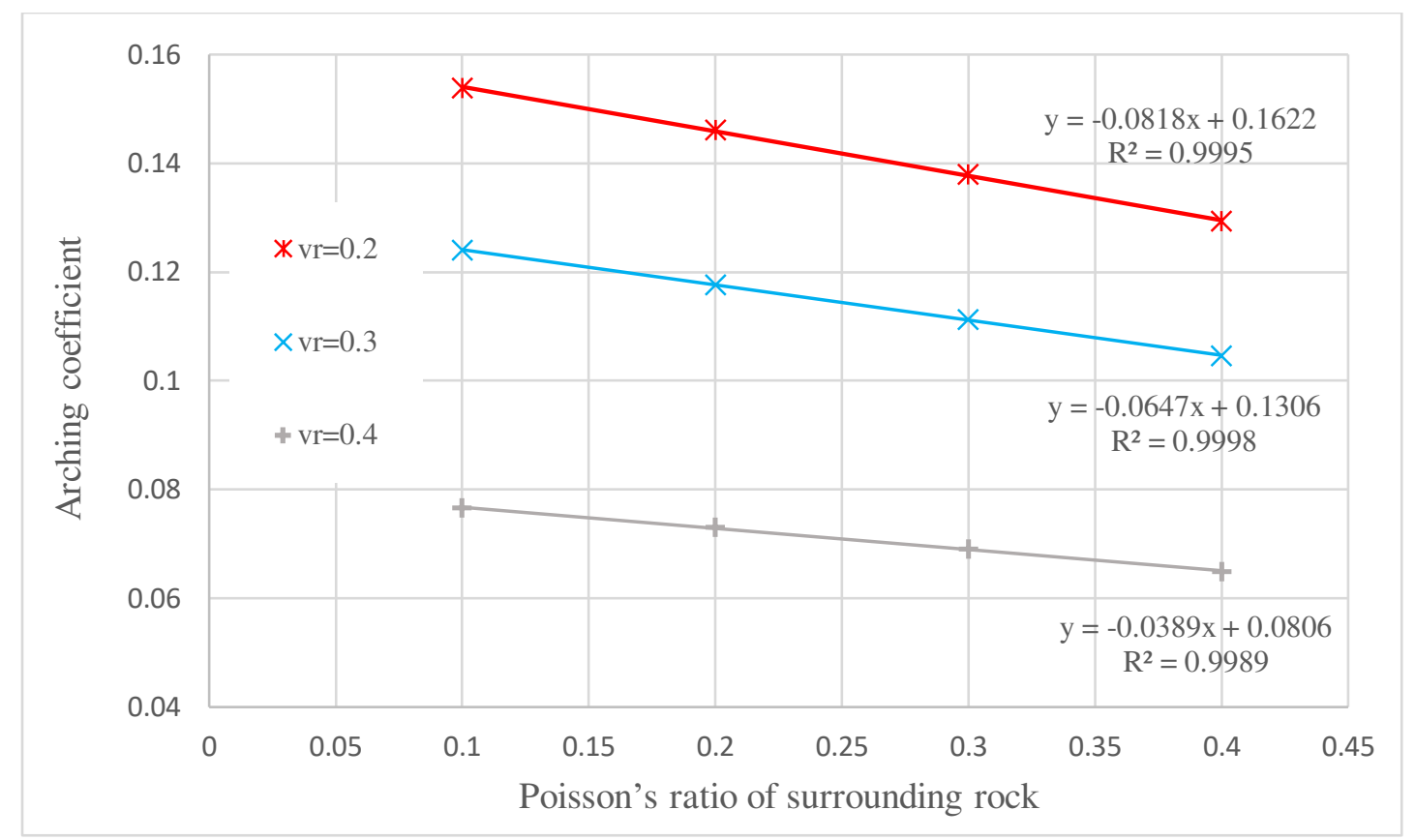

Figure 7. Variations of the arching coefficient by changing vs and different values of $v_{\mathrm{r}}$ In addition to the effect of two common elastic parameters, Young's modulus and Poisson's ratio, the effect of the Biot coefficient on the stress paths and reservoir compaction was investigated in this paper. The Biot coefficient is one of the most important parameters determining the geomechanical behavior of a pro-elastic environment and playing a principal role in determining the acting effective stresses on the reservoir rock (Fang et al. 2018; Salemi et al. 2018). Usually in the calculation of reservoir compaction for simplification, assuming the compressibility of grain is sufficiently lower than the rock frame, the Biot coefficient is considered equal to 1 . According to the Biot effective stress theory, the effective stress in a pro-elastic medium is equal to (Skempton 1984):

$$
\sigma^{\prime}=\sigma-\alpha P_{\mathrm{P}}
$$

Where $\alpha$ is the Biot coefficient which depends on the ratio of grains to rock frame bulk modulus (Wang 2000). Theoretically, the Biot coefficient value varying from 0 to 1 , but the experimental results suggest that the Biot coefficient ranges from 0.65 to 0.91 for the most reservoir rocks (Salemi et al. 2018). 
To determine the effect of the Biot coefficient on the stress arching coefficient and the compaction drive mechanism, the reservoirs were modeled by considering three different Biot coefficient values, $0.65,0.8$, and 0.95 . The reservoirs have elastic parameters similar to the surrounding rock $(v r=v s=0.3$ and $\mathrm{Er}=5 \mathrm{GPa})$ and, as before, assuming three aspect ratios of $\mathrm{D} / \mathrm{r}=1,2,3$. The stress arching coefficient in the center of the modeled reservoirs is presented in the Figure 8.

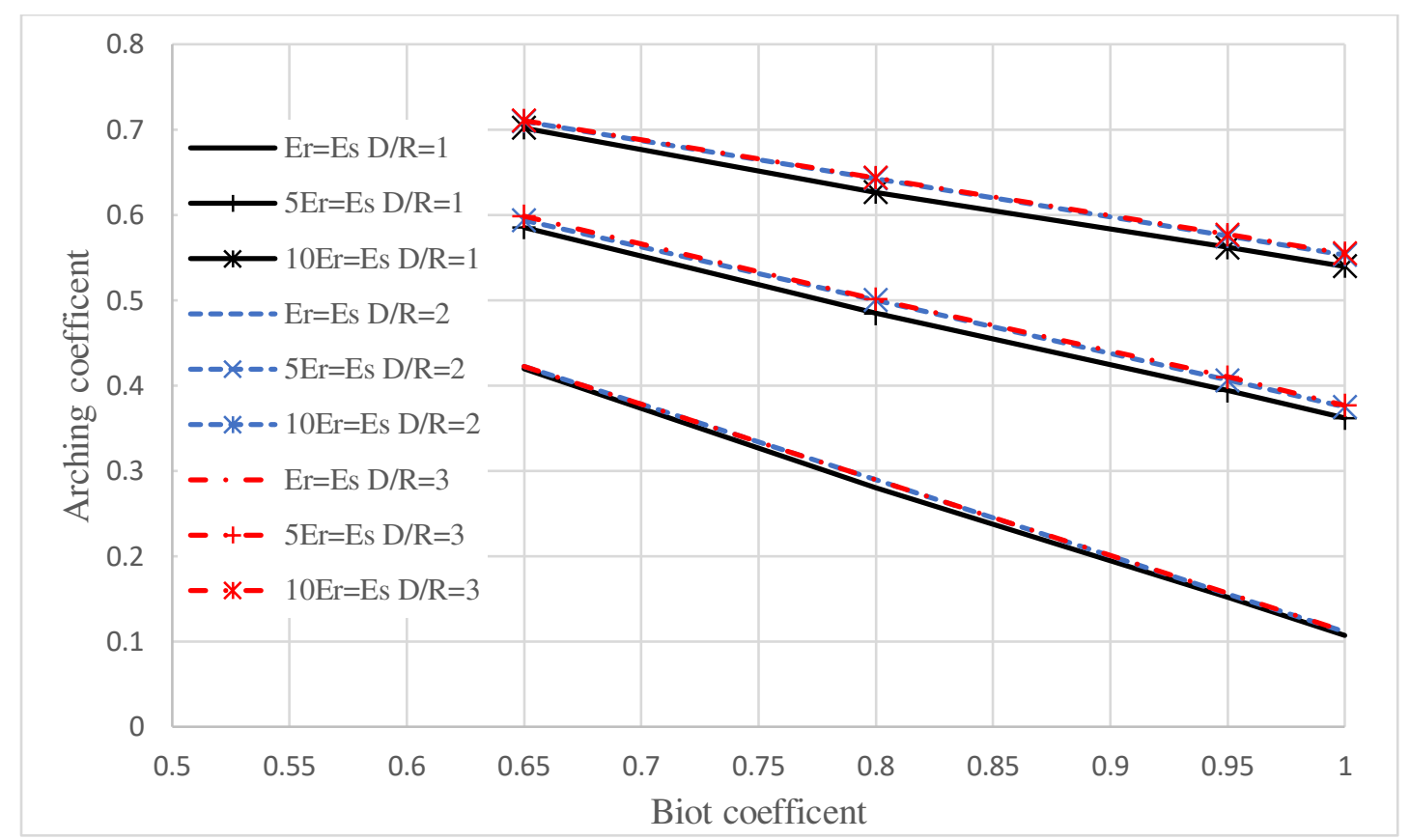

Figure 8. Effect of consideration of Biot coefficient on the arching coefficient

As is shown in Figure 8, minimum values of the stress arching coefficient were obtained by considering the Biot coefficient equal to 1 , and its effect on the effective stress is neglected. An important point to consider in almost traditional reservoir compaction models, even in cases where the stress arching is considered, is to assume a certain value for the stress path coefficients over the entire reservoir. This value is usually estimated based on numerical or analytical modeling along the central axis of the reservoir. While the results of numerical modeling show that the values of the stress path coefficients are different both in the horizontal direction and in the vertical direction. Figure 9 shows the trend of changes of the stress path coefficients along the horizontal and vertical central axes of the reservoir. Like Figures 1-3, 
Figure 9 shows the results of modeling a reservoir located at a depth of $2000 \mathrm{~m}$ with a ratio of $\mathrm{E}_{\mathrm{s}} / \mathrm{E}_{\mathrm{r}}=5$.
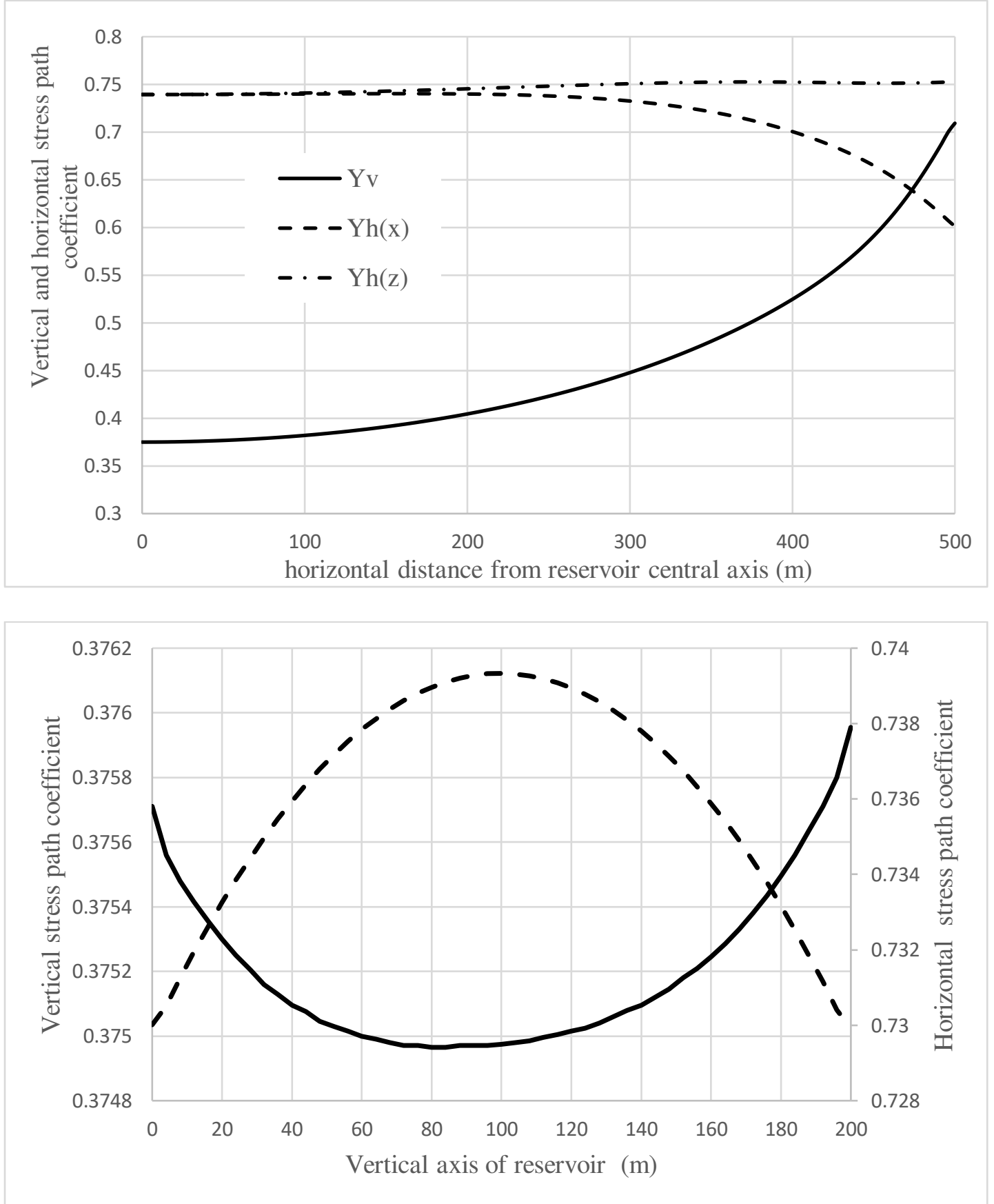

Figure 9. The horizontal and vertical stress path coefficient changes along the central axes of the reservoir, a) horizontal axis b) vertical axis

As can be seen in Figure 9, the central axis of the reservoir has the lowest value of the vertical stress path coefficient, which indicates the occurrence of the lowest arching and that 
minimizing reduction in the total vertical stress in the reservoir central part than other sections. In contrast, in the reservoir flanks, most changes are made in the vertical stress and the arching coefficient is maximum.

The horizontal stress path showed a different trend from the vertical stress path. It is maximum in the middle part of the reservoir that indicates the closeness of the value of changes in the total horizontal stress value with the pore pressure decrease.

However, toward the reservoir sides due to stress arching the amount of the total horizontal stress increased, and therefore, the reduction of total stress created by the pore pressure reduction in these parts is less than the central part of the reservoir.

\section{5- Modeling the effects of stress arching on the compression drive mechanism}

The pores compressibility $\left(\mathrm{C}_{\mathrm{pp}}\right)$ of the modeled reservoirs due to using the same elasticity parameters for the reservoir rock in all models, based on Equation 4 is equal to $0.59 \mathrm{GPa}^{-1}$. Also, change in the pore volume induced by pore pressure dropping of $20 \mathrm{MPa}$ will be equal to $0.00297 \mathrm{~m}^{3}$ per unit the volume $\left(1 \mathrm{~m}^{3}\right)$ of the reservoir rock. The calculated values for compressibility and pore volume reduction are the maximum possible values, and the reservoir compaction modeling indicates that these values will not be achieved due to the stress arching occurrence.

At a first glance, the amount of the reservoir pores compaction and the resulting oil extraction may seem insignificant, but with respect to the total volume of oil within the modeled reservoirs, the compaction can remove $1.2 \%$ of the total in situ reservoir oil. Given that at the best case only 30 to 40 percent of the in situ oil can be extracted, this value will account for about 3 to 4 percent of the possible produced oil from the reservoir.

Figure 10 shows volumes of the reservoir pores compaction that is equal to the amount of oil produced due to the compaction drive mechanism. In this Figure, the amount of oil recovered 
without considering the stress arching and the modeling results obtained by the ABAQUS are presented for 10 modeling status.

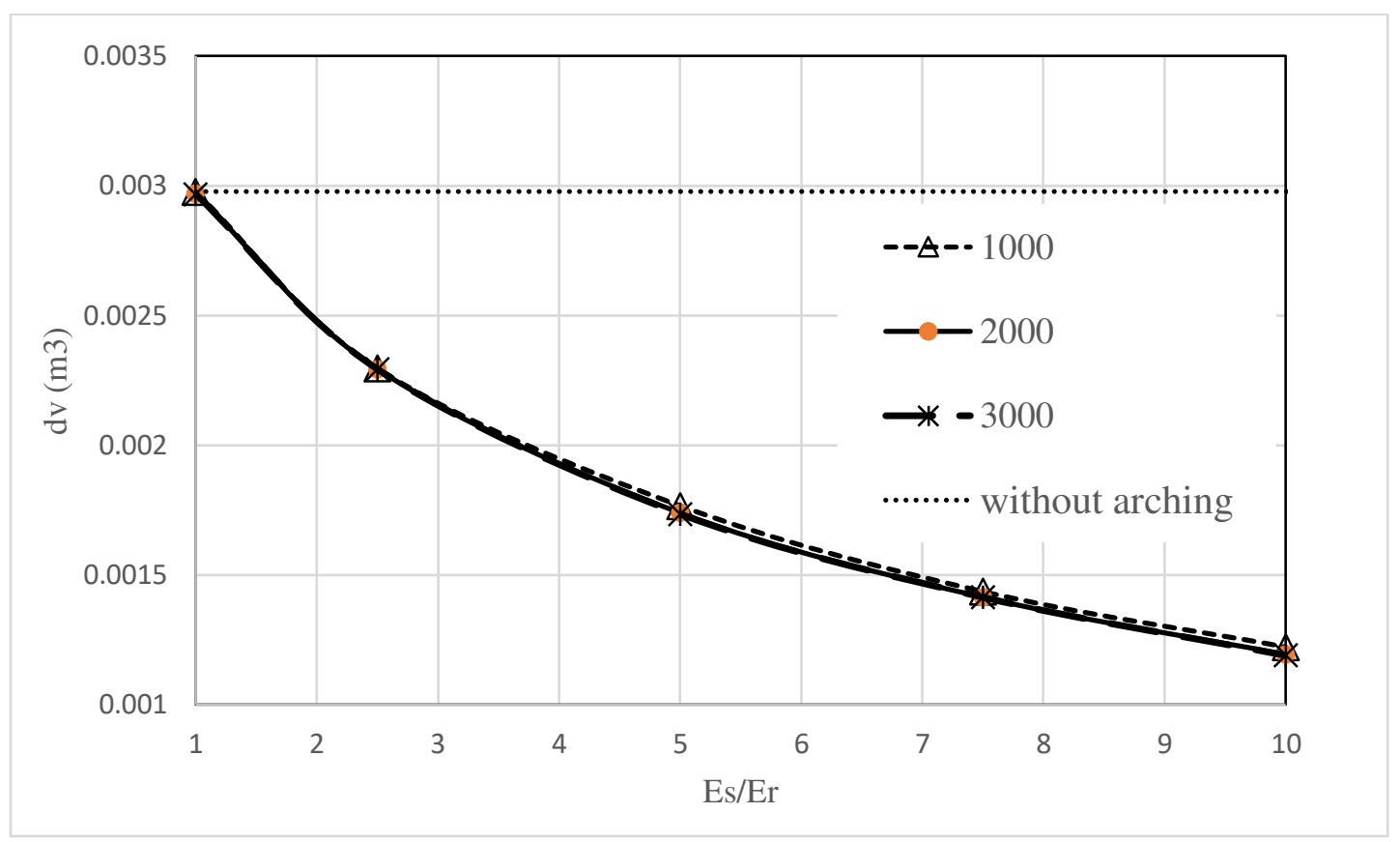

Figure 10. The effect of stress arching on the oil recovery due to compression drive mechanism

As can be seen in Figure 10, in all three D/r ratios when the elastic modulus of the reservoir and the surrounding rock are the same, the reservoir pore volume reductions obtained by numerical modeling and the amount calculated using Equation 5 are almost identical. A closer look at the models reveals that the cause of this equality between results in all three $\mathrm{D} / \mathrm{r}$ ratios, is not due to the absence of stress arching but due to the increase of horizontal stresses in the flanks of the reservoir as a result of the vertical stress concentration in these sections (Figure 11a).

Figure $11 \mathrm{~b}$ shows the changes in the three main stress paths and their averages along the horizontal axis of a reservoir which has the same elastic modulus with the surrounding rock. The interesting point about the reservoir stress paths is that none of them follows the existing relationships based on the uniaxial compression model $(\gamma v \neq 0$ and $\gamma \mathrm{h} \neq(1-2 v) /(1-v) \gamma)$, while the average stress path showed a good matching with its value obtained from Equation 3. 

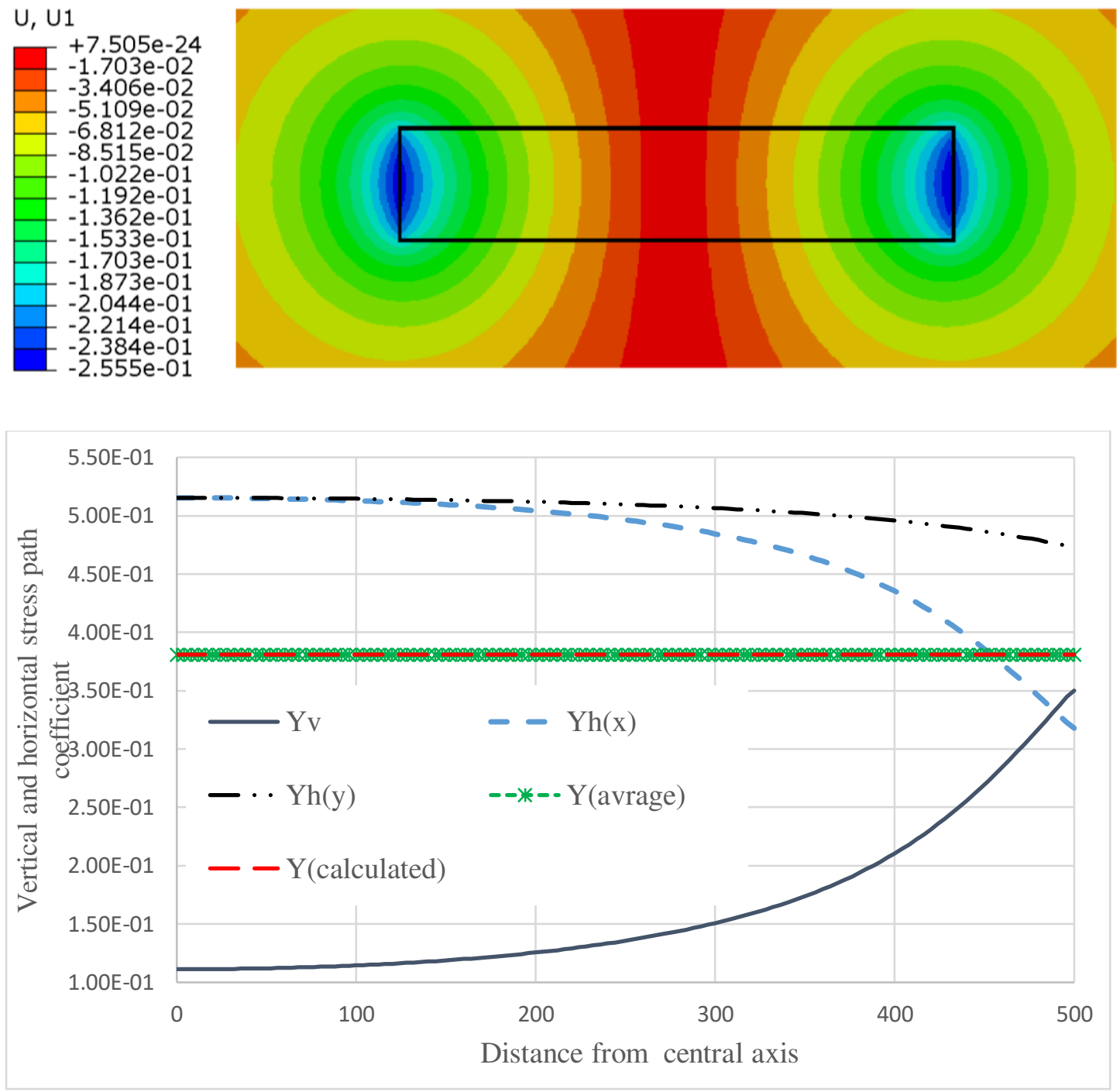

Figure 11. a) Horizontal displacement occurred in the reservoir and its surrounding environment due to the reservoir depletion, b) Vertical and horizontal stress path coefficients of the reservoir when the reservoir rock elastic parameters are the same with its surrounding rock.

Therefore, equality of pore volume reduction obtained by numerical modeling and the uniaxial compaction model when $\mathrm{E}_{\mathrm{r}}=\mathrm{E}_{\mathrm{s}}$ does not mean that the stress arching will not affect the distribution of the stresses acting on the reservoirs. The occurrence of stress arching, especially in reservoir rocks with stress sensitivity permeability, for example, fractured reservoir rocks, even if it does not affect the final compaction it can play an important role in the reservoir performance. The stress arching by reducing the increment ratio of the effective stress in some 
parts of the reservoir can be led to maintain a higher percentage of the initial permeability of the reservoir rock in these parts. However, the occurrence of stress arching can increase the stresses applied to other parts of the reservoir (sides) and increase the compaction and decrease the permeability of these parts, simultaneously. Experiments by Wang et al. (2013) to investigate the effect of stress arching on reservoir rock permeability showed that if the stress arching coefficient is 0.12 , about $23 \%$, and if the stress arching coefficient is 0.28 , about $50 \%$, the permeability of rock will be higher than the case in which the stress arching coefficient is equal to zero (Wang et al., 2013).

Modeling reservoirs with different Poisson's ratio showed that variation of this parameter has not an important effect on the reservoir compaction and on the ultimate oil recovery by the compaction drive mechanism. In Figure 12, the modeling results of reservoirs with different Poisson's ratios which is equal to the surrounding rock is presented.

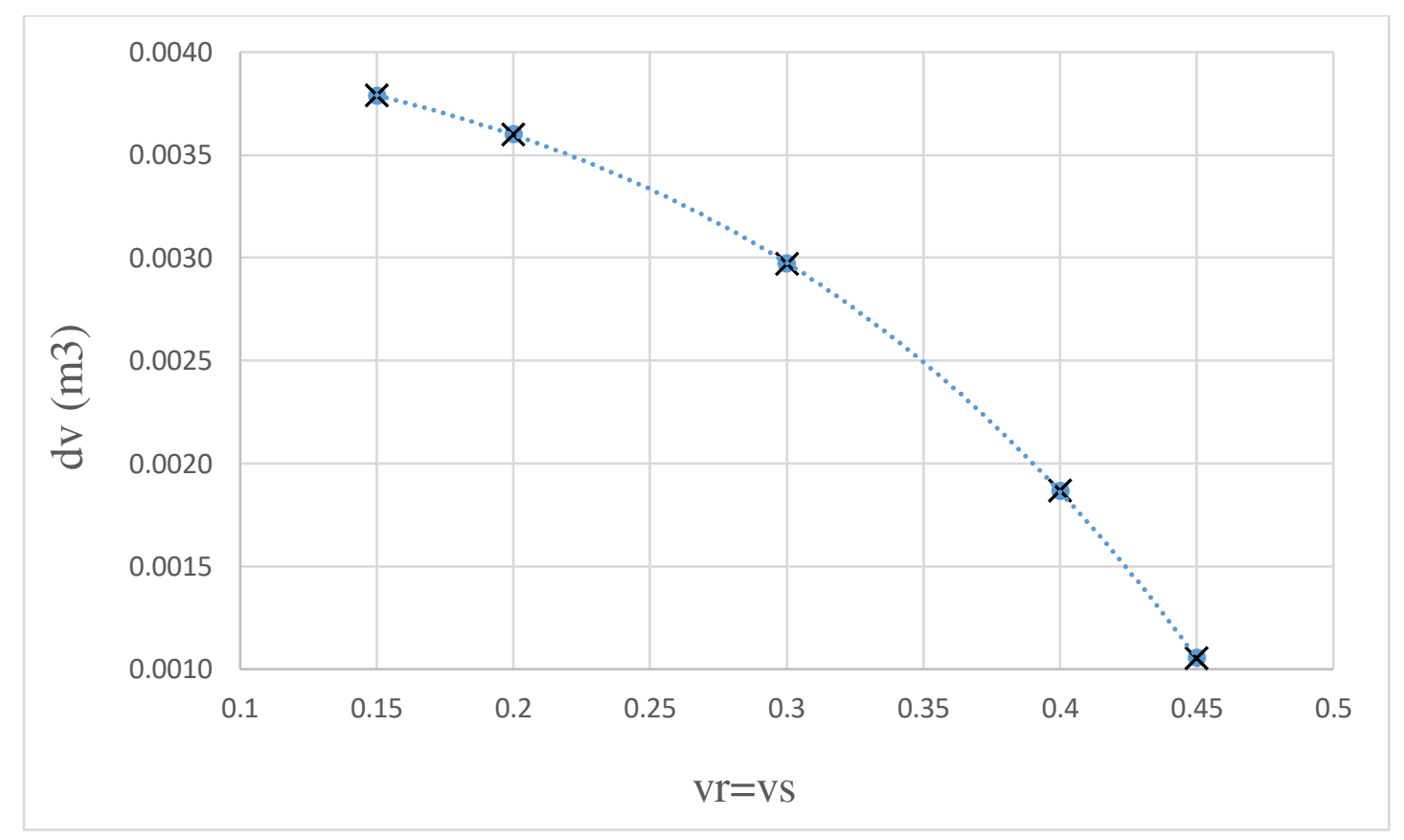

Figure 12. Effect of variation of Poisson's ratio on the compaction drive mechanism It should be noted that the trend of decreasing the reservoir compaction with the increase of the Poisson's ratio is a direct result of a decrease in the compressibility of the reservoir rock, and the stress arching has no significant effect on it. 
In Figure 13 variations of dv with change of the Poisson's ratio of the surrounding rock are presented. The reservoir Poisson's ratio is considered constant in each modeling set and results are plotted on one line. As the results show, in cases that the Poisson's ratio of the surrounding rock is considered less than the reservoir rock, reservoir compaction is less than the amount calculated by the uniaxial model. But, by increasing the Poisson's ratio of the surrounding rock and exceeding from the Poisson's ratio of the reservoir rock, the compaction of the reservoir will increase.

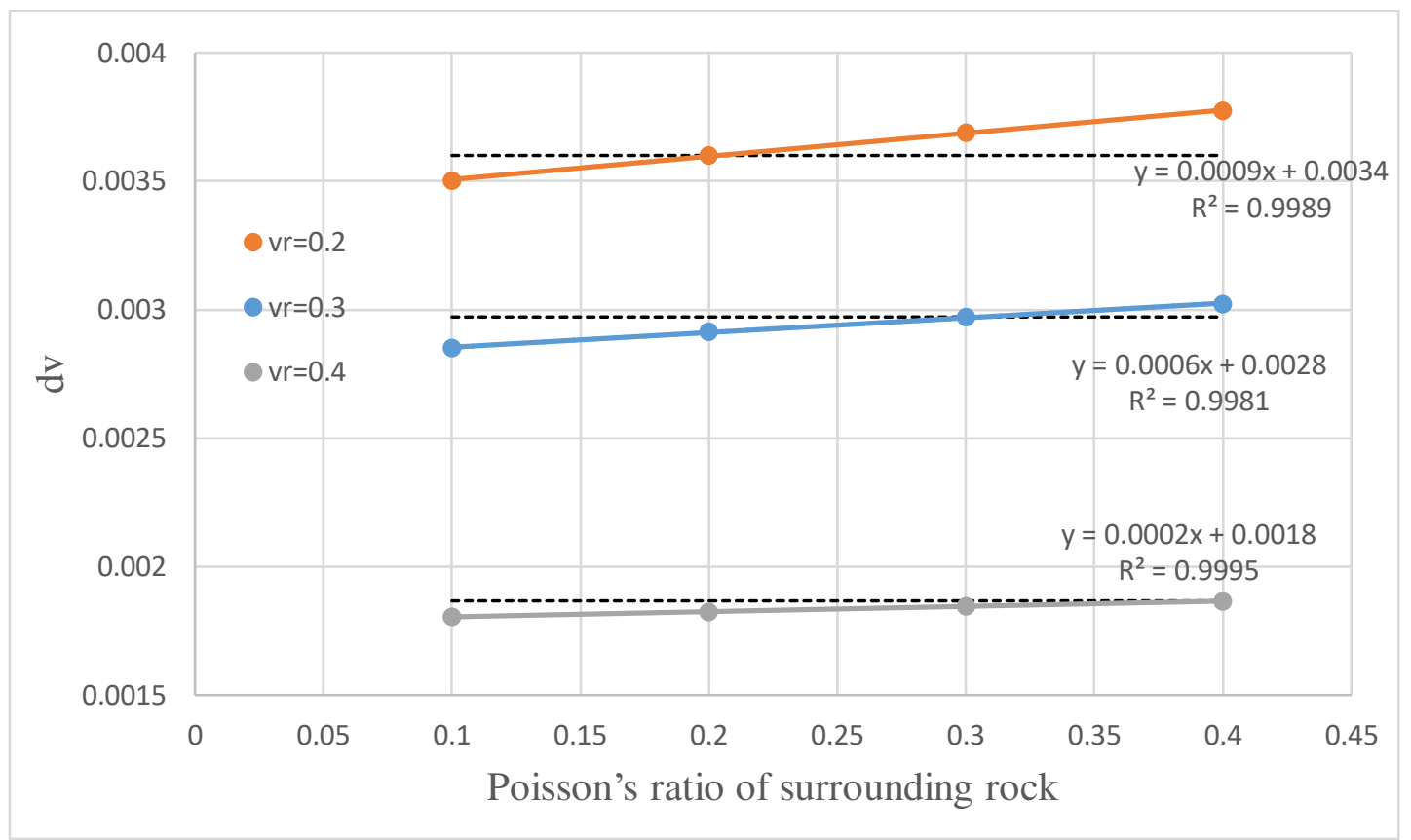

Figure 13. Effect of variation of Poisson's ratio of the reservoir and surrounding rocks on the reservoir compaction. Dashed lines are shown the reservoir compaction calculated by the uniaxial compaction model.

The effect of Biot coefficient on the reservoir compressibility is very different from the two considered parameters, the Poisson's coefficient and Young's modulus. The Biot coefficient effect on the reservoir compaction is also dependent on the ratio of Young's modulus of the reservoir and the surrounding rock $\left(\mathrm{E}_{\mathrm{r}} / \mathrm{E}_{\mathrm{s}}\right)$. As shown in Figure 14, when Young's modulus of the reservoir and the surrounding rock are equal, increasing the Biot coefficient increases the compaction of the reservoir and the maximum value of the $\mathrm{dv}$ is achieved by considering the 
Biot coefficient equal to one. But, with increasing the Young's modulus ratio, $\mathrm{E}_{\mathrm{r}} / \mathrm{E}_{\mathrm{s}}$, the increasing trend of reservoir compaction with increasing of the Biot coefficient slows down and even in the high $\mathrm{E}_{\mathrm{r}} / \mathrm{E}_{\mathrm{s}}$, this trend can be reversed.

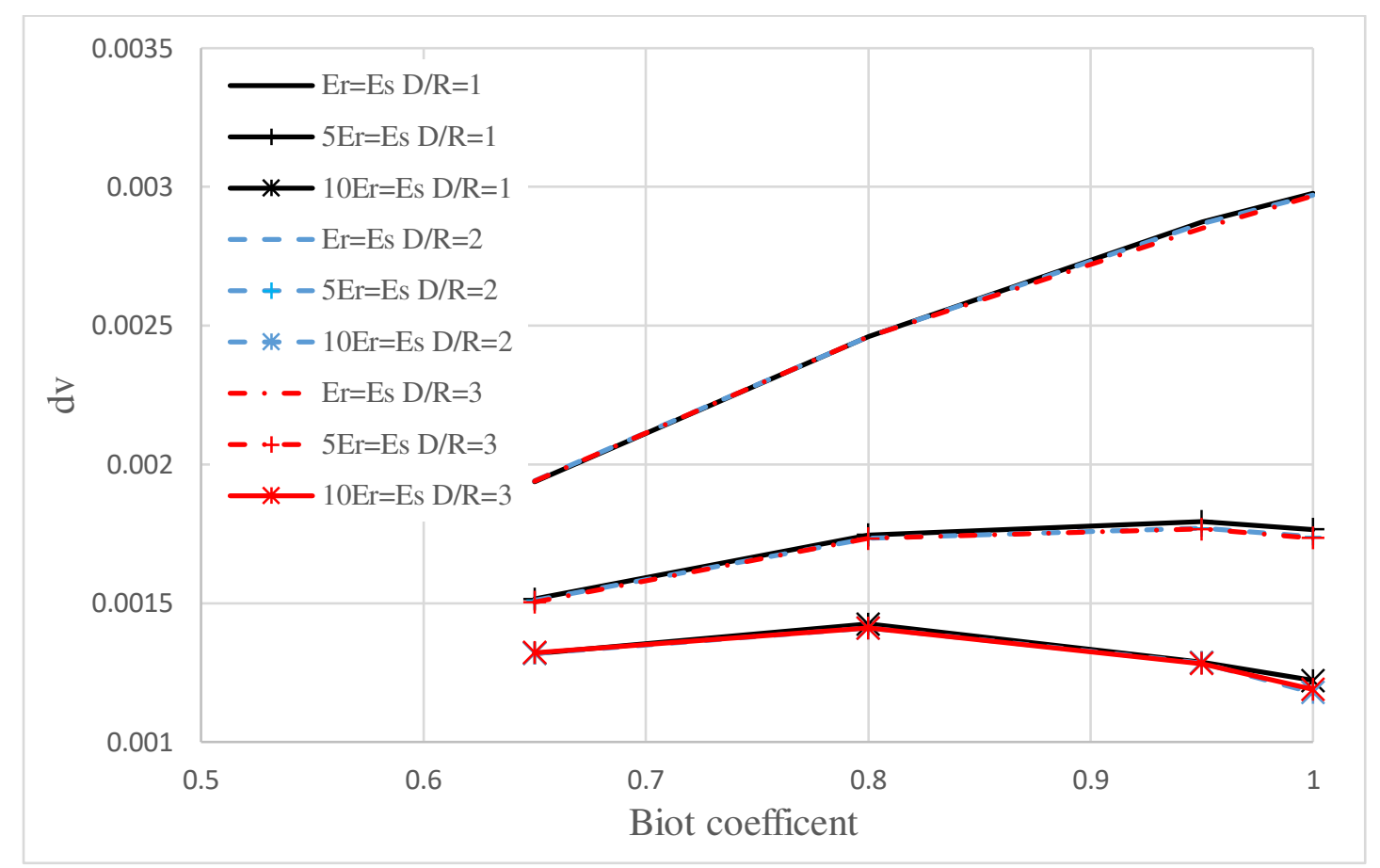

Figure 14. Effect of variation Biot coefficient on the compaction drive mechanism.

As shown in Figure 14, ignoring the Biot coefficient in reservoirs that have the same Young's modulus or near to the surrounding rocks can lead to an overestimate of the oil produced by the compaction drive mechanism. However, in fields where there is a significant difference between Young's modulus of the reservoir rock and the surrounding environment, the effect of the Biot coefficient on the reservoir compaction is greatly reduced.

\section{6- Conclusion}

In this paper, the effect of stress arching on reservoir compaction and compaction drive mechanism was investigated. Compaction drive is one of the four known mechanisms of oil recovery, which, although in most fields has a smaller share than the other three mechanisms, its role cannot be ignored in the oil recovery. 
The results of reservoir depletion modeling using ABAQUS software indicated that the stress path coefficients, which are key parameters in the reservoir compaction, are very different from the results obtained based on the pro-elastic relations and uniaxial compaction model. The modeling indicated Young's modulus contrast between the reservoir and the surrounding rock have the greatest impact on the reservoir compaction. Accordingly, the maximum reservoir compaction is obtained when the elastic modulus of the reservoir and the surrounding rock are the same, in this case the reservoir geometry does not affect its compaction volume, and the reservoir compaction will be equal to the calculated value based on the uniaxial compaction model. However, it should be noted that even in this case, the stress path coefficients are different from the values calculated based on the uniaxial compression model and the effect of stress arching on distribution of stresses and other parameters affected by it, such as reservoir permeability and compressibility cannot be neglected.

Investigating of the Poisson's ratio variation indicated both the absolute value of this parameter and contrast between the Poisson's ratio of the reservoir and surrounding rock affected the stress path and the reservoir compaction. Based on modeling results when $v_{\mathrm{r}} / v_{\mathrm{s}}<1$ the reservoir compaction will be greater than the calculated value from the uniaxial compaction model and vice versa.

Moreover, modeling the Biot coefficient effect on the reservoir stress paths and reservoir compaction, showed the effect of this parameter, in addition to its value, depends on the $E_{\mathrm{r}} / \mathrm{E}_{\mathrm{s}}$. In the reservoirs that have the same or near Young's modulus with the surrounding rock, $\mathrm{E}_{\mathrm{r}} \approx \mathrm{E}_{\mathrm{s}}$, there is a direct relationship between the Biot coefficient value and reservoir compaction. But in a very softer reservoir than the surrounding rock, $\mathrm{E}_{\mathrm{r}} / \mathrm{E}_{\mathrm{s}} \approx 0.1$, the Biot coefficient has a weak and irregular effect on the reservoir compaction.

\section{Reference}


Asaei H, Moosavi M, Aghighi MA (2018) A laboratory study of stress arching around an inclusion due to pore pressure changes Journal of Rock Mechanics and Geotechnical Engineering 10:678-693

Dake LP (2001) The practice of reservoir engineering (revised edition). Elsevier,

Dusseault MB (2011) Geomechanical challenges in petroleum reservoir exploitation KSCE Journal of Civil Engineering 15:669-678

Fang Y, Shi Y, Sheng Y, Zhang Z (2018) Modeling of Biot's coefficient for a clay-bearing sandstone reservoir Arabian Journal of Geosciences 11:302

Fjar E, Holt RM, Raaen A, Risnes R, Horsrud P (2008) Petroleum related rock mechanics vol 53. Elsevier,

Gao C, Gray K (2020) Infill well wellbore stability analysis by considering plasticity, stress arching, lateral deformation and inhomogeneous depletion of the reservoir Journal of Petroleum Science and Engineering 195:107610

Haug C, Nüchter J-A, Henk A (2018) Assessment of geological factors potentially affecting production-induced seismicity in North German gas fields Geomechanics for Energy and the Environment 16:15-31

Hedayatikhah S, Abdideh M (2019) 3D Geomechanical Modeling of Casing Collapse in Plastic Formations (Cap Rock of Hydrocarbon Reservoir) Natural Resources Research 28:273286

Hettema M, Schutjens P, Verboom B, Gussinklo H (2000) Production-induced compaction of a sandstone reservoir: the strong influence of stress path SPE Reservoir Evaluation \& Engineering 3:342-347

Holt R, Flornes O, Li L, Fjær E Consequences of depletion-induced stress changes on reservoir compection and recovery. In: Gulf rocks 2004, the 6th north America rock mechanics symposium (NARMS), 2004. American Rock Mechanics Association,

Khan M, Teufel LW, Zheng Z Determining the effect of geological and geomechanical parameters on reservoir stress path through numerical simulation. In: SPE Annual Technical Conference and Exhibition, 2000. Society of Petroleum Engineers,

Mulders FMM (2003) Modelling of stress development and fault slip in and around a producing gas reservoir

Orlic B, Wassing B (2013) A study of stress change and fault slip in producing gas reservoirs overlain by elastic and viscoelastic caprocks Rock Mechanics and Rock Engineering 46:421-435

Peng K, Shi S, Zou Q, Zhang Y, Tan G (2020) Gas Permeability Characteristics and Energy Evolution Laws of Gas-Bearing Coal under Multi-Level Stress Paths Natural Resources Research:1-22

Radwan A, Sen S (2020) Stress Path Analysis for Characterization of In Situ Stress State and Effect of Reservoir Depletion on Present-Day Stress Magnitudes: Reservoir Geomechanical Modeling in the Gulf of Suez Rift Basin, Egypt Natural Resources Research:1-16

Salemi H, Iglauer S, Rezagholilou A, Sarmadivaleh M (2018) Laboratory measurement of Biot's coefficient and pore pressure influence on poroelastic rock behaviour The APPEA Journal 58:182-189

Sanni M (2018) Petroleum Engineering: Principles, Calculations, and Workflows vol 237. John Wiley \& Sons,

Sayers CM, Schutjens PM (2007) An introduction to reservoir geomechanics The Leading Edge 26:597-601

Segura J et al. (2011) Reservoir stress path characterization and its implications for fluid-flow production simulations Petroleum Geoscience 17:335-344 
Skempton A (1984) Effective stress in soils, concrete and rocks Selected papers on soil mechanics 1032:4-16

Soltanzadeh H, Hawkes CD (2008) Semi-analytical models for stress change and fault reactivation induced by reservoir production and injection Journal of Petroleum Science and Engineering 60:71-85

Sulak R (1991) Ekofisk field: the first 20 years Journal of Petroleum Technology 43:1,265261,271

Wang HF (2000) Theory of linear poroelasticity with applications to geomechanics and hydrogeology vol 2. Princeton University Press, 
Figures

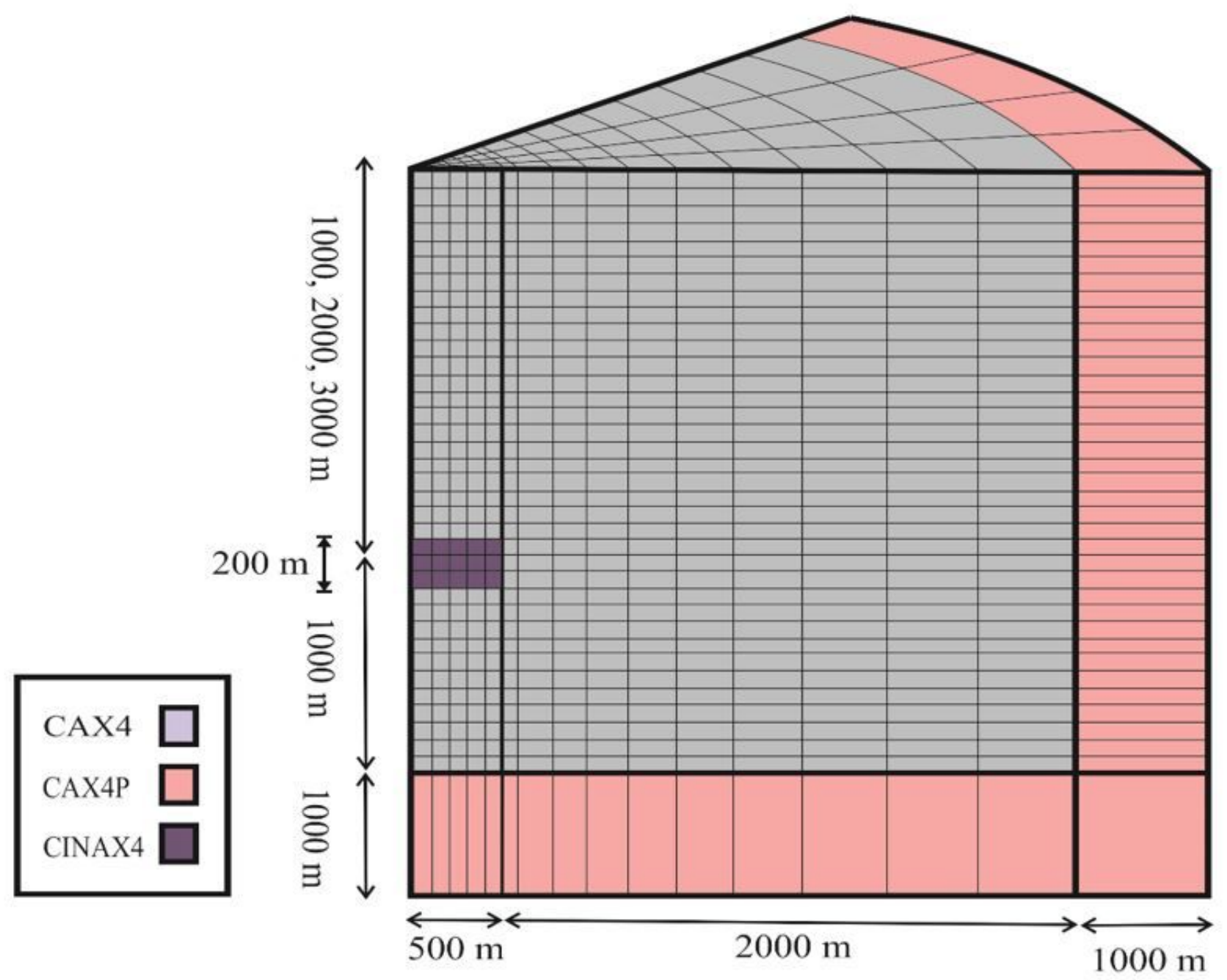

Figure 1

Numerical model: mesh scheme and element type 


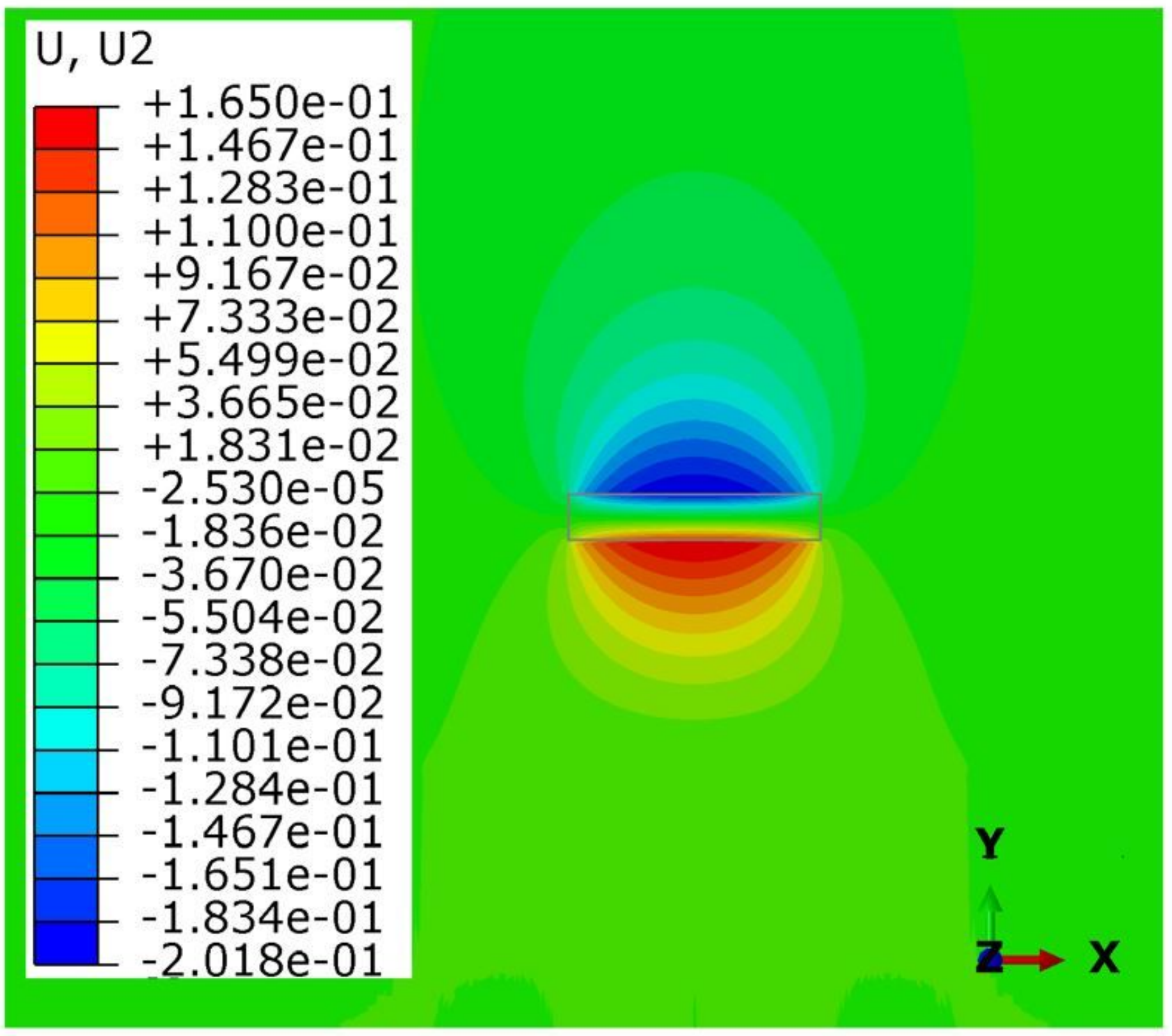

Figure 2

The vertical displacement around the depleted reservoir and raising the lower part of the reservoir due to the vertical stress reduction 


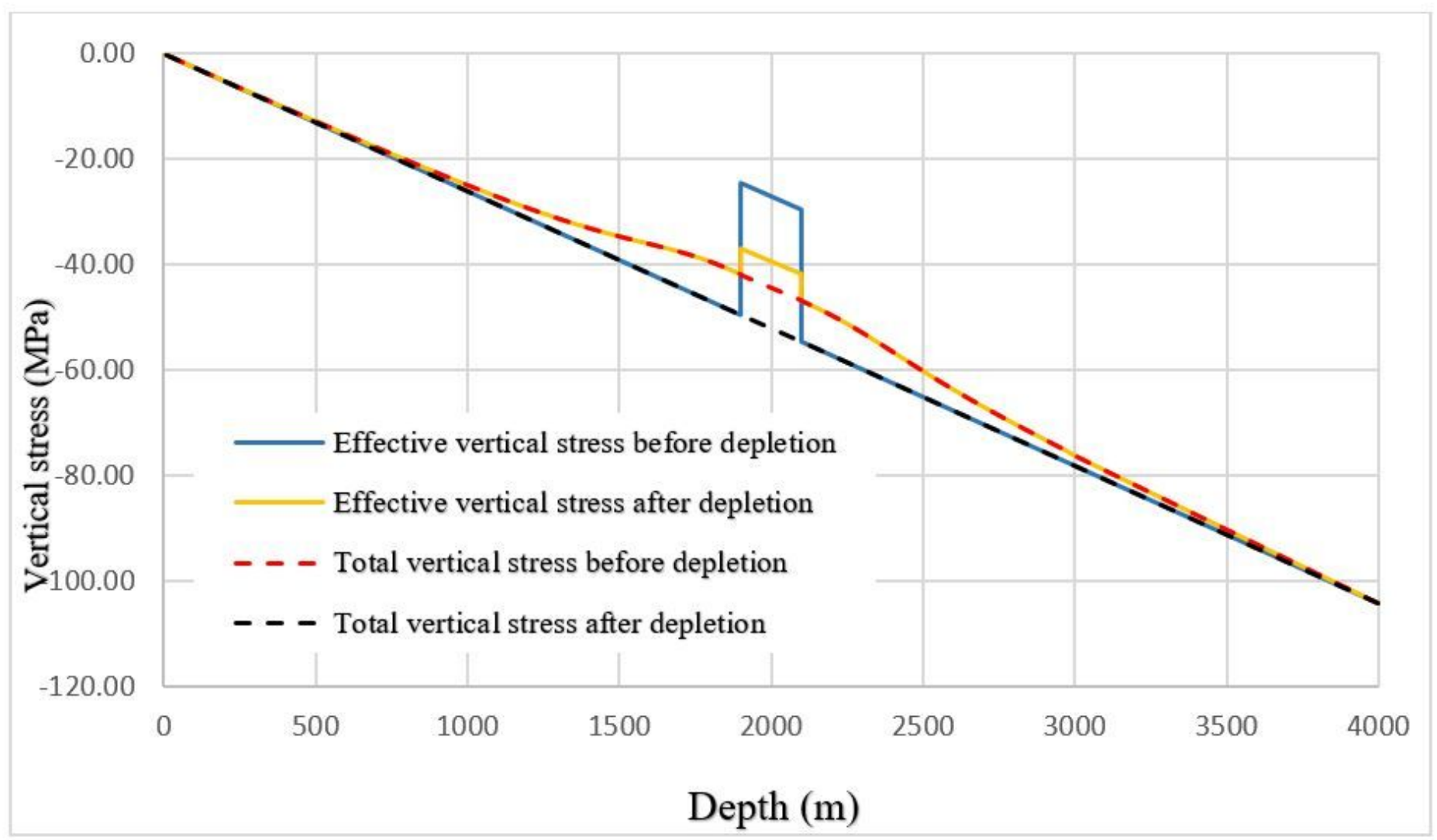

Figure 3

Effective vertical stress changes along the central axis of the reservoir 


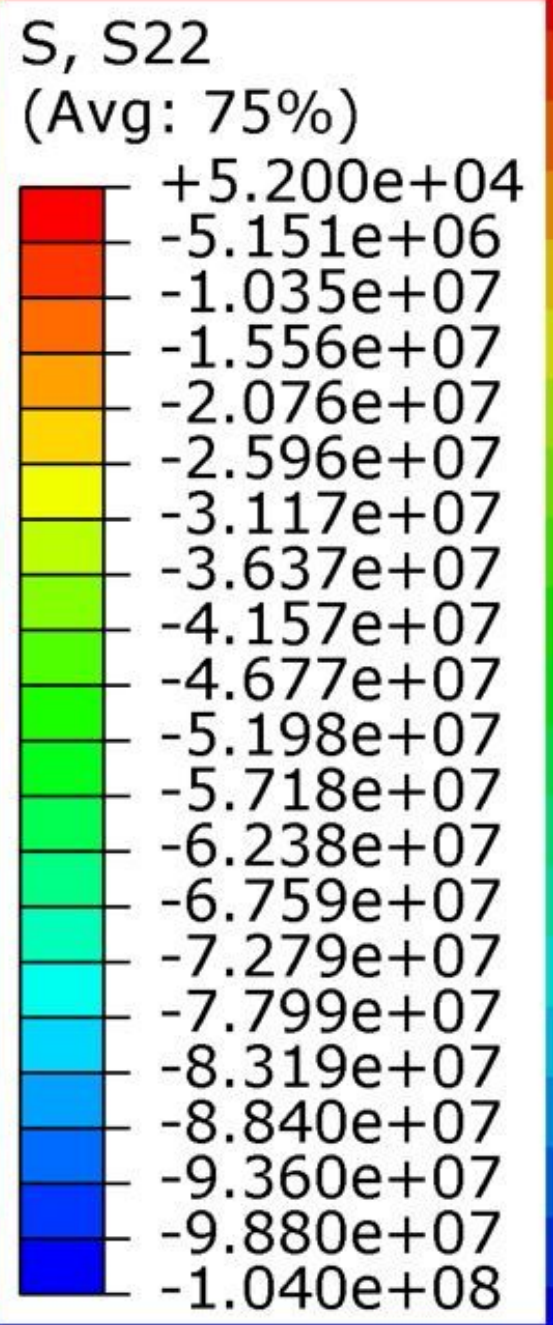

Figure 4

The effective vertical stress changes in the reservoir and its surrounding rock 


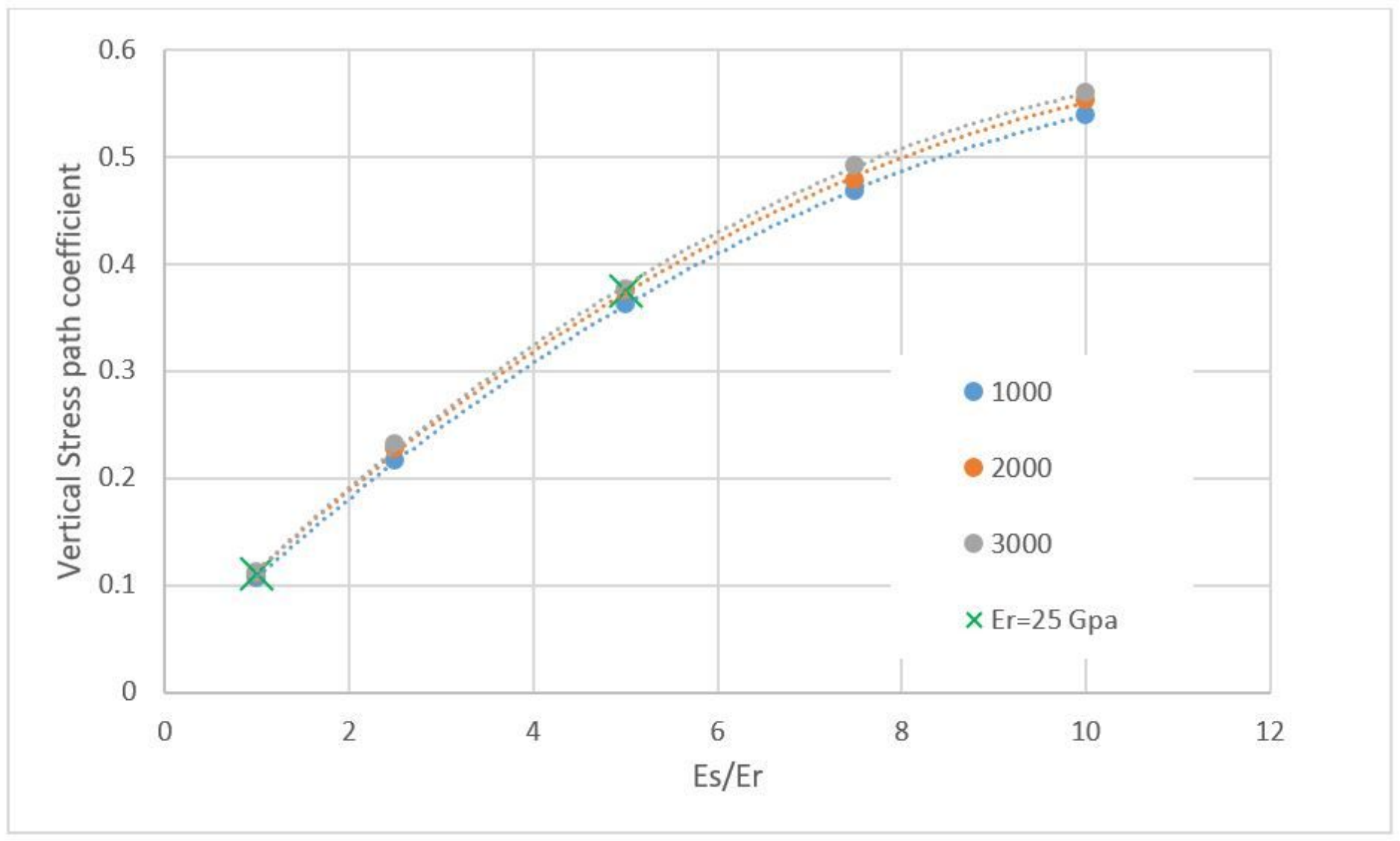

Figure 5

The vertical stress path in different $\mathrm{D} / \mathrm{r}$ and Es/Er ratios 


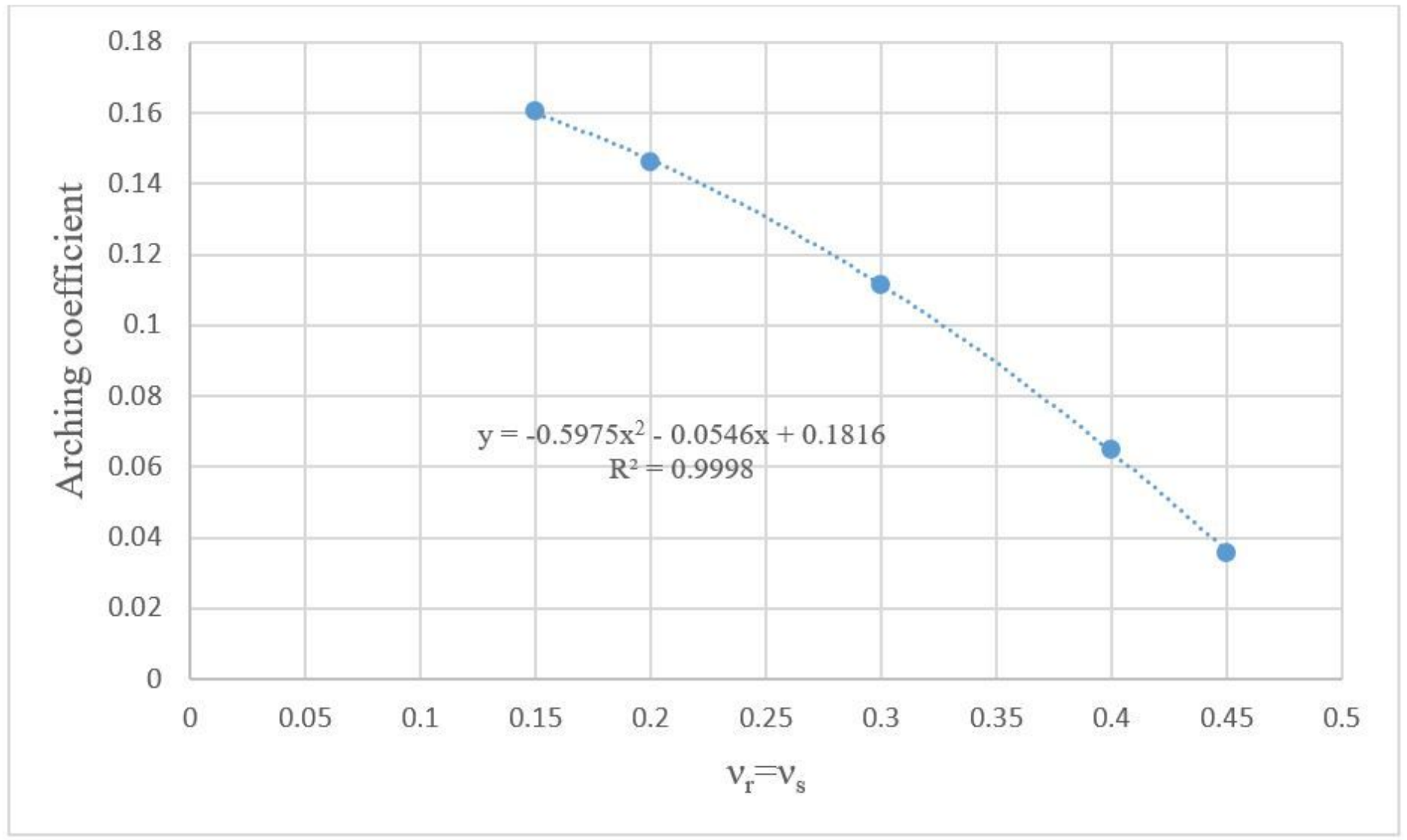

Figure 6

Effect of Poisson's ratio changes in the vertical stress path coefficient. 


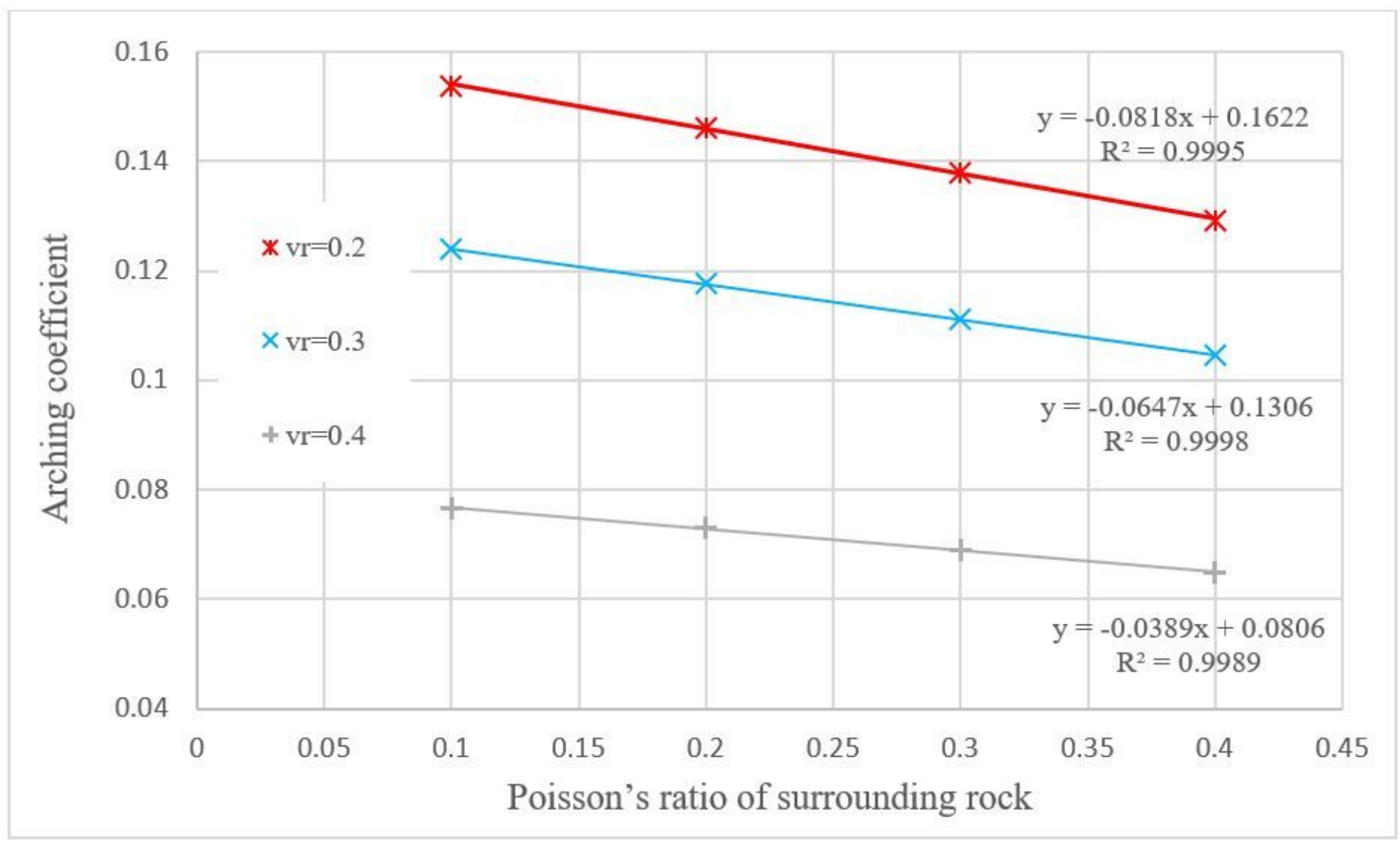

Figure 7

Variations of the arching coefficient by changing vs and different values of $\mathrm{vr}$ 


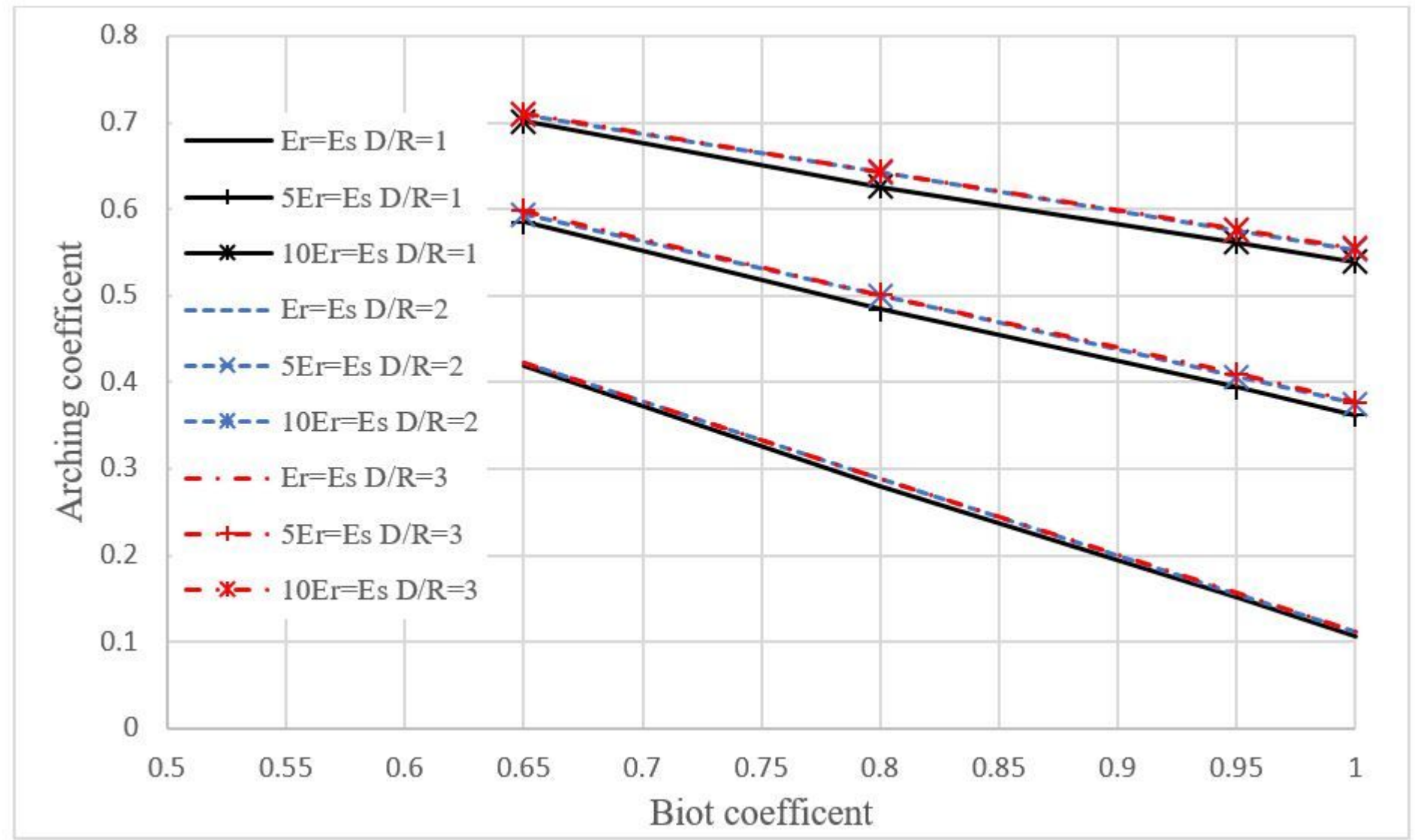

Figure 8

Effect of consideration of Biot coefficient on the arching coefficient 

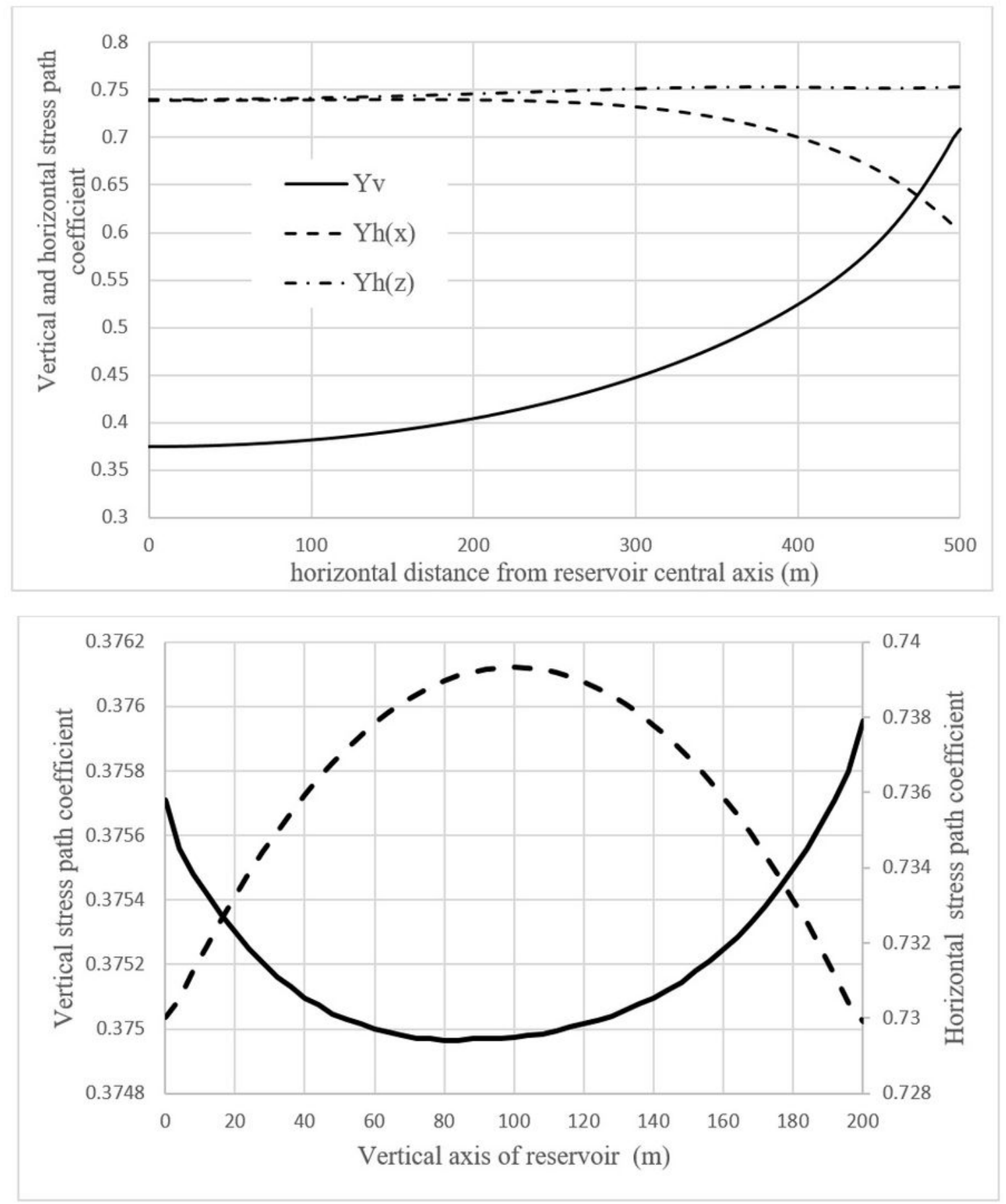

\section{Figure 9}

The horizontal and vertical stress path coefficient changes along the central axes of the reservoir, a) horizontal axis b) vertical axis 


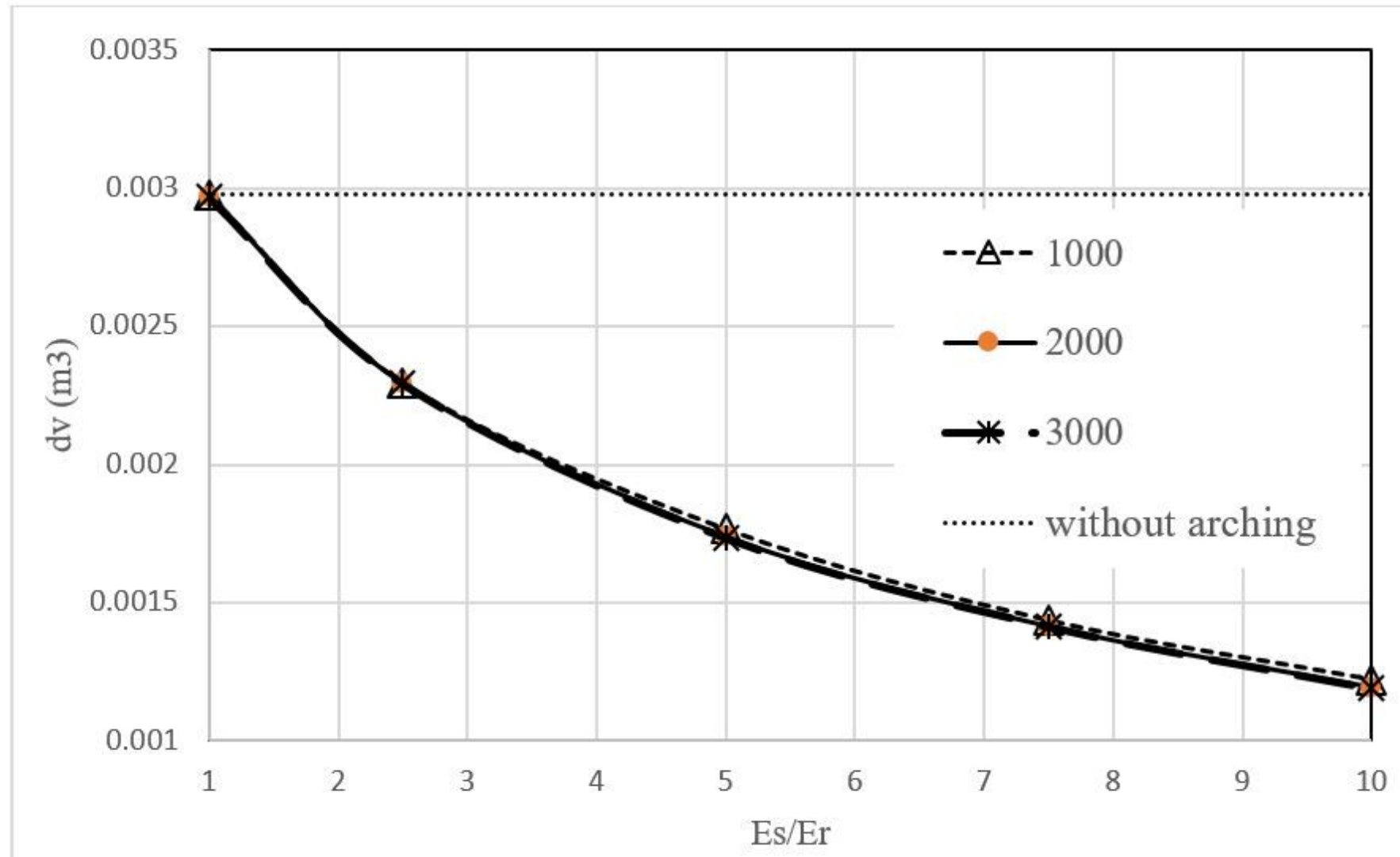

Figure 10

The effect of stress arching on the oil recovery due to compression drive mechanism 

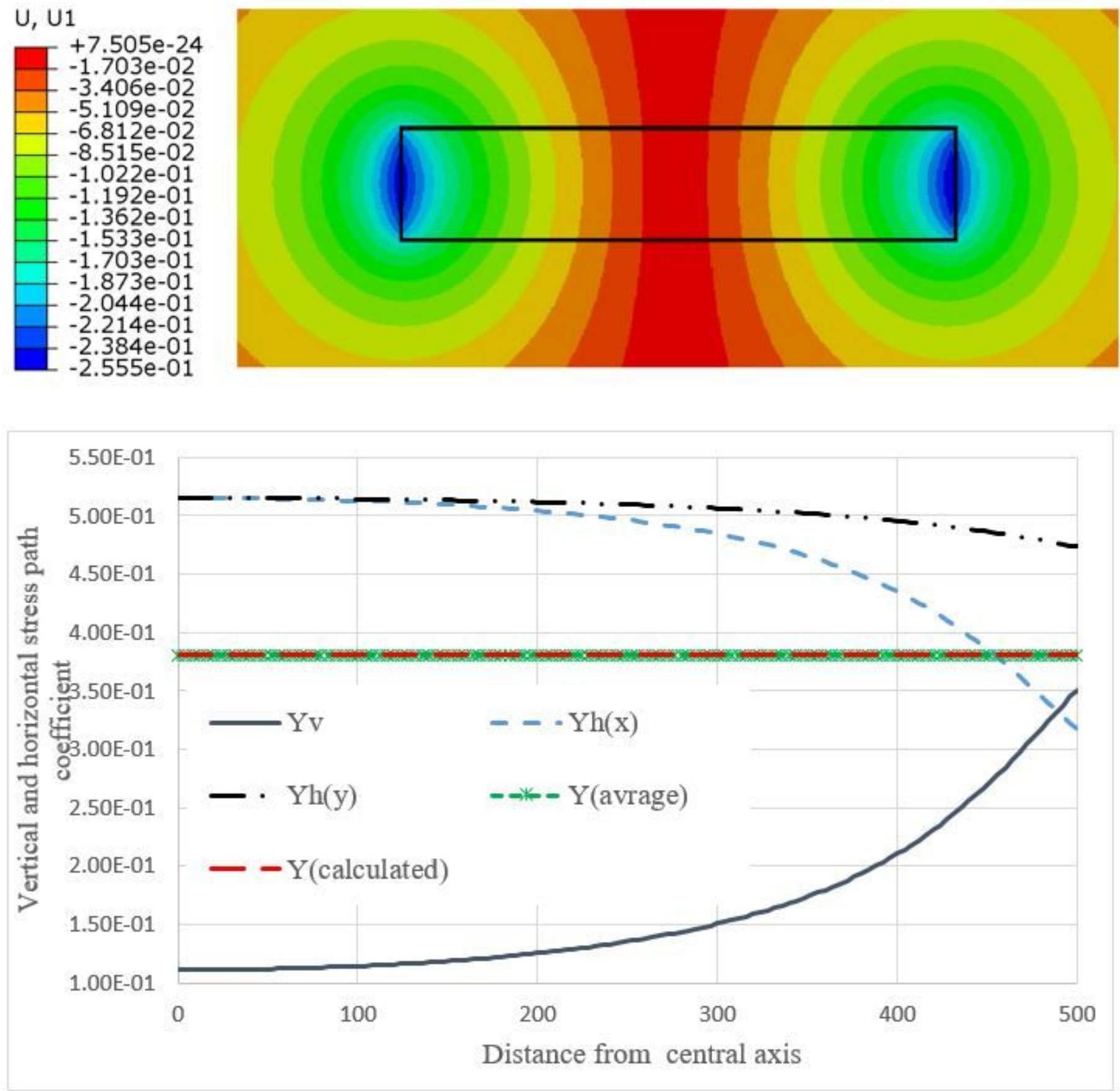

\section{Figure 11}

a) Horizontal displacement occurred in the reservoir and its surrounding environment due to the reservoir depletion, b) Vertical and horizontal stress path coefficients of the reservoir when the reservoir rock elastic parameters are the same with its surrounding rock. 


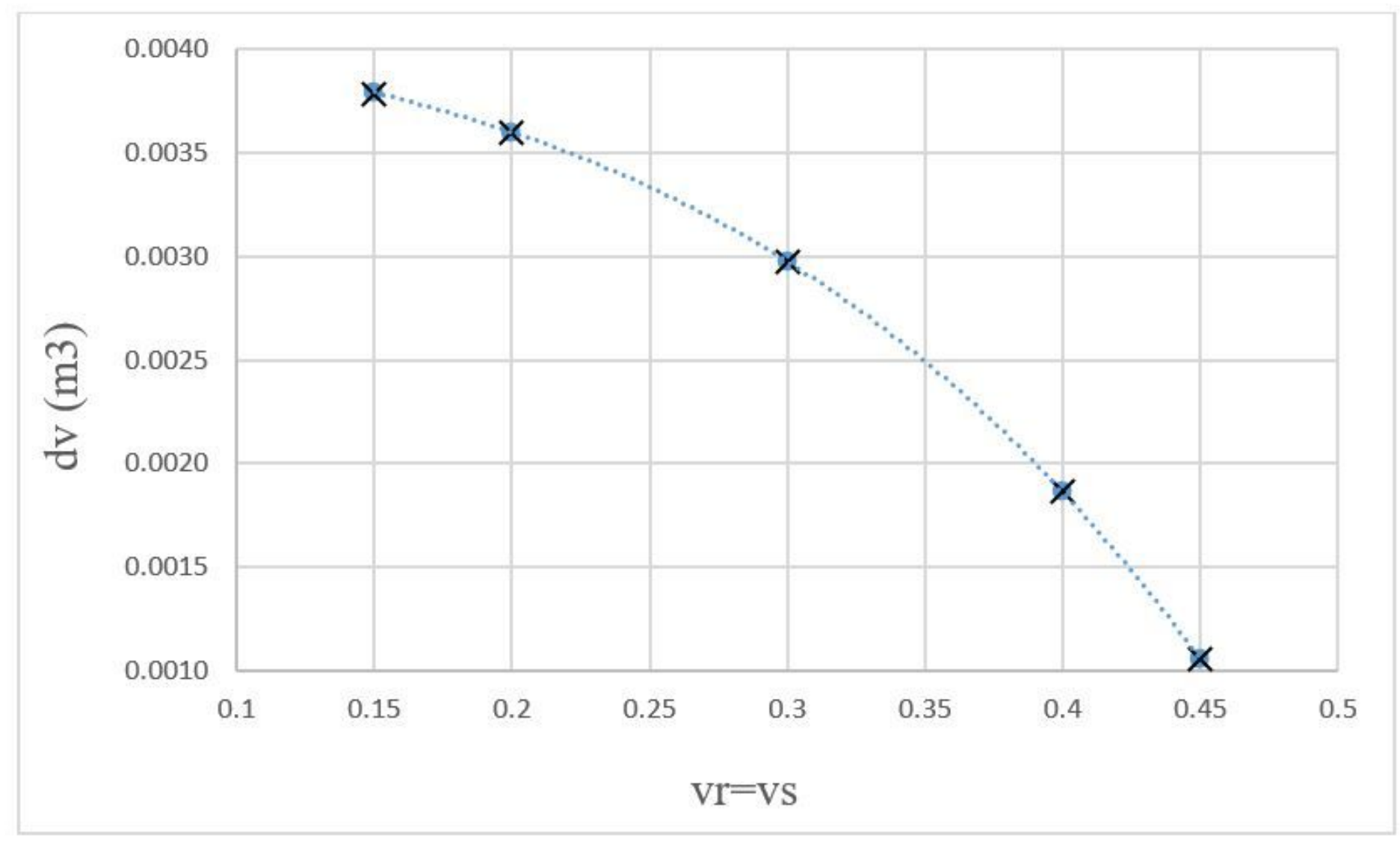

Figure 12

Effect of variation of Poisson's ratio on the compaction drive mechanism It should be noted that the trend of decreasing the reservoir compaction with the increase of the Poisson's ratio is a direct result of a decrease in the compressibility of the reservoir rock, and the stress arching has no significant effect on it. 


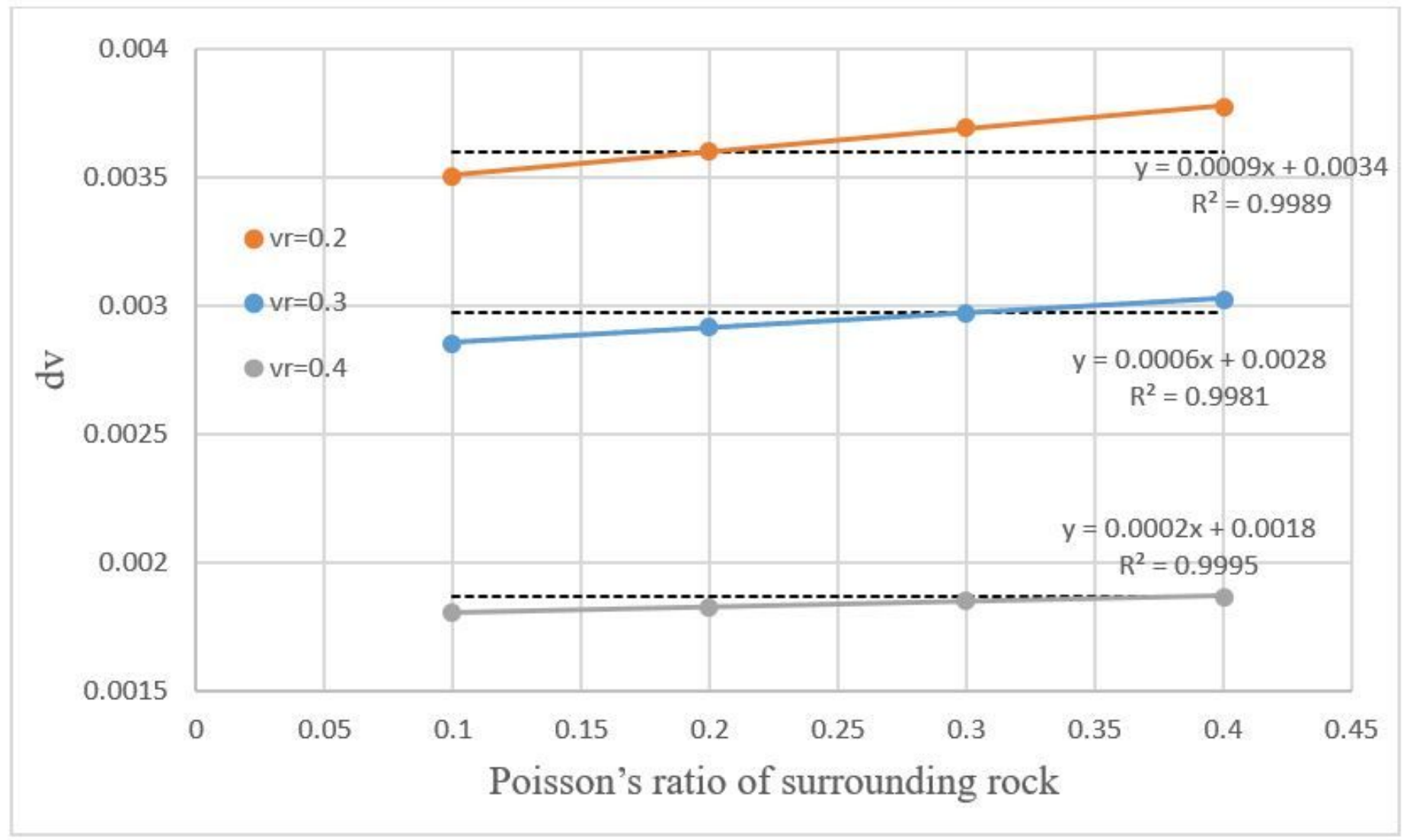

\section{Figure 13}

Effect of variation of Poisson's ratio of the reservoir and surrounding rocks on the reservoir compaction. Dashed lines are shown the reservoir compaction calculated by the uniaxial compaction model. 


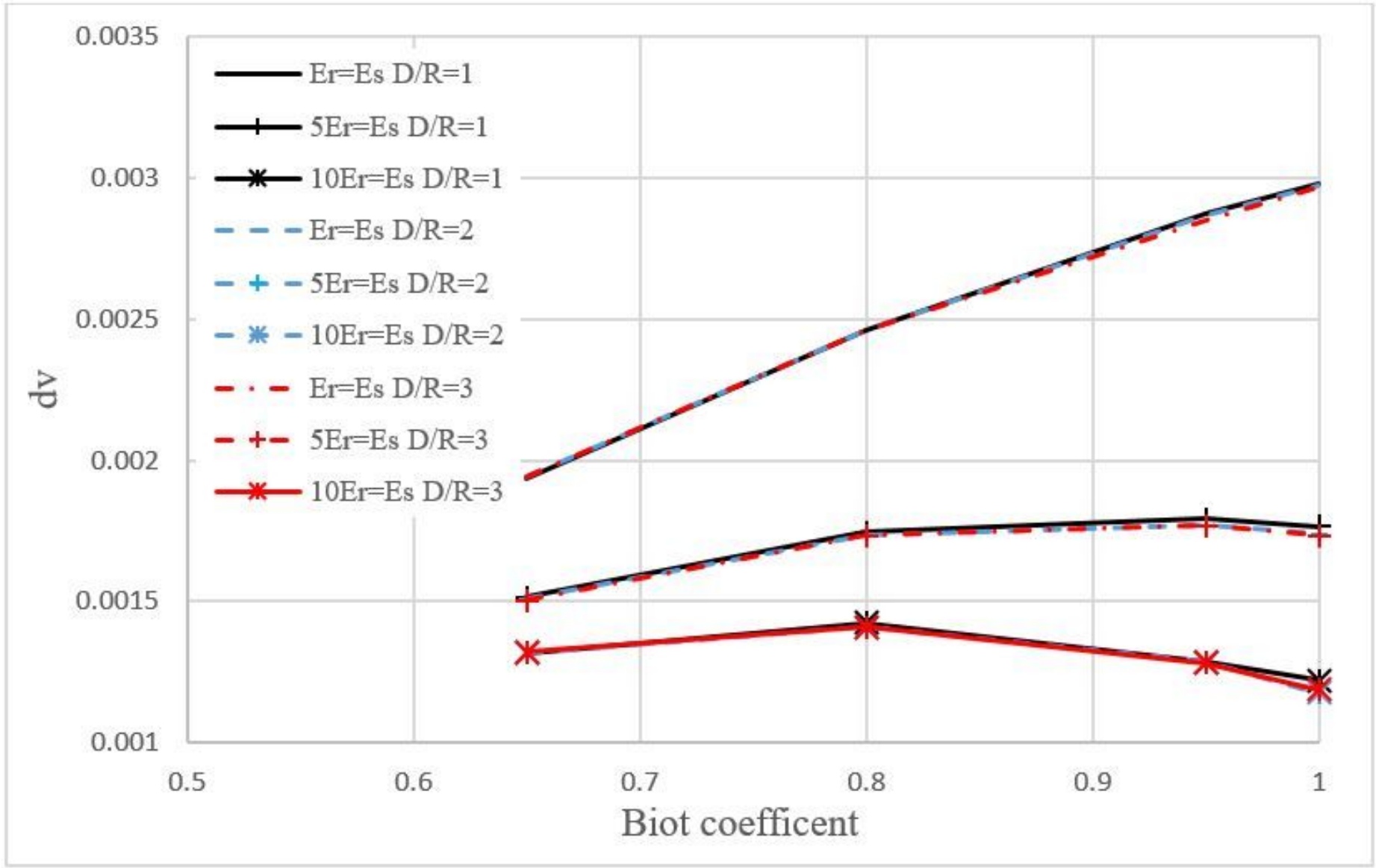

Figure 14

Effect of variation Biot coefficient on the compaction drive mechanism. 